\title{
LA ADMINISTRACIÓN DEL RECONOCIMIENTO MUTUO Un análisis a partir de la libre circulación de profesionales... hasta la unidad de mercado ${ }^{1}$
}

\author{
Jorge Agudo GonZÁLEZ \\ Profesor Titular de Derecho Administrativo \\ Universidad Autónoma de Madrid
}

\begin{abstract}
RESUMEN
El reconocimiento mutuo es un principio estructural del mercado interior que determina los términos en que se concretan las relaciones cooperativas horizontales entre Administraciones de los Estados miembros. Desde esta perspectiva formal, cabría decir que el principio supera su carácter conflictual original (país de origen), para hacer prevalecer su vertiente cooperativa, estableciendo reglas de «división del trabajo» entre Administraciones nacionales. En el artículo se afronta este análisis tomando como sector de referencia la libre circulación de profesionales. Esta elección no es casual, pues la configuración formal del principio también tiene una orientación finalista determinante: la efectividad de las libertades comunitarias. Ese elemento sienta las bases para la construcción de un Derecho administrativo ex parte civium que tiene como premisa la elección del Derecho aplicable en un contexto de competencia entre ordenamientos. Esa decisión, que corresponde en exclusiva a los ciudadanos titulares de las libertades europeas, confiere una relevancia determinante a la autonomía de la voluntad con consecuencias en la prescriptividad de las normas, en el (no)ejercicio de las competencias propias por las Administraciones del país de destino o de acogida, en la trascendencia de las relaciones interadministrativas o en el otorgamiento de plena validez a actos con eficacia supranacional. Por último, la aplicación del principio también plantea la generación de efectos discriminatorios inversos respecto de relaciones jurídicas domésticas similares a las gobernadas por aquel principio en sede europea. La evitación de ese efecto mediante la expansión voluntaria del reconocimiento mutuo es una solución que ha sido llevada a su máxima expresión en nuestro país con la Ley de Garantía de la Unidad de Mercado.
\end{abstract}

Palabras clave: libre circulación de profesionales; reconocimiento mutuo; elección del Derecho aplicable; cooperación administrativa; actos administrativos transnacionales; discriminación inversa.

1 Este trabajo se enmarca en el proyecto de investigación, financiado por la Universidad Autónoma de Madrid, «La Administración Pública del Mercado Interior Europeo» (CEMU2013-08). 


\begin{abstract}
The mutual recognition is a structural principle of the internal market that determines the terms in which the horizontal cooperative relations between national administrations take place. From this formal perspective, the principle has overcome its original conflictual legal nature, to assert their cooperative side, establishing rules for the "division of functions» between national authorities. In this paper the analysis takes as sectorial reference the free movement of professionals. This choice is not accidental, since the formal configuration of the principle has a decisive teleological orientation: the effectiveness of the freedoms of movement. That finalist element provides the basis for the reform of Administrative Law from an ex parte civium perspective whose premise is the choice of law in a context of competition between national legal orders. That decision, which exclusively corresponds to citizens holders of the rights recognized by the European Law, confers a decisive relevance to autonomy of the will, with consequences on the binding effect of legal provisions, or concerning the (non)exercise of powers as well as, in the framework of inter-administrative relationships, giving full effect to supranational administrative acts. Finally, the implementation of mutual recognition poses the generation of reverse discriminatory effects concerning similar domestic legal relationships. The avoidance of this consequence through voluntary expansion of mutual recognition is a solution that has been carried out to its ultimate expression with the Market Unity Act.
\end{abstract}

Key words: free movement of professionals; mutual recognition; choice of law; administrative cooperation; transnational administrative acts; reverse discrimination.

\title{
SUMARIO
}

I. INTROdUCCIÓN.-II. Elementos ESTRUCTURALES Y RECONOCIMIENTO MUTUO: 1. Procedimientos horizontales y actos transnacionales: A) El reconocimiento de cualificaciones profesionales: a) Actividades profesionales y libre prestación de servicios. b) Actividad profesional y libertad de establecimiento. B) El principio de reconocimiento mutuo como principio ordenador de procedimientos complejos: una Administración funcionalmente integrada. 2. El principio de reconocimiento mutuo como principio directivo para la creación de una estructura organizativa (débil) de colaboración y asistencia. 3. Conclusión: la vertiente formal del principio de reconocimiento mutuo gobierna de forma determinante la programación de la actuación administrativa.-III. EL PRINCIPIO DE RECONOCIMIENTO MUTUO Y LA CONSTRUCCIÓN DE UN DERECHO ADMINISTRATIVO EUROPEO EX PARTE CIVIUM: 1. La programación formal al servicio de los objetivos sustantivos. 2. Titularidad de derechos, elección del Derecho aplicable y sometimiento a la supralegalidad europea. 3. La integración del Derecho Público con principios de Derecho Privado: la relevancia de la autonomía de la voluntad: A) Premisa. La competencia entre ordenamientos y la elección del Derecho aplicable y de la Administración de acogida. B) La relevancia de la autonomía de la voluntad en el Derecho Administrativo. C) Afección a la legitimidad de la actuación administrativa.-IV. REFLEXIONES FINALES. DISCRIMINACIÓN INVERSA Y EXTENSIÓN DEL RECONOCIMIENTO Mutuo: La Ley de UnidAd de Mercado.-Bibliografía. 


\section{INTRODUCCIÓN}

El artículo 57.1 del Tratado de Roma de 1957 (actual artículo 54.1 del TFUE) fue la primera referencia en el Derecho Europeo al principio de reconocimiento mutuo vinculada a las libertades básicas del mercado interior ${ }^{2}$. El precepto preveía la facultad del Consejo para adoptar las Directivas necesarias con el fin de aplicar la regla de reconocimiento mutuo tanto en lo relativo al reconocimiento de los títulos y diplomas, como respecto a las condiciones en las que habría de producirse el acceso y el ejercicio a ciertas profesiones. Esta afirmación choca con el entendimiento habitual que atribuye la formulación del principio a la STJCE de 20 de febrero de 1979 (Cassis de Dijon) en el ámbito de la libre circulación de mercancías. Sin embargo, se ha de reconocer que aquel precepto no tuvo nunca la misma trascendencia práctica que la sentencia Cassis de Dijon.

Otra consideración que el Tratado de Roma en su redacción original permite contraponer es la supuesta disociación entre armonización de legislaciones y reconocimiento mutuo. Si algo demuestra la literalidad del viejo artículo 57 es la complementación in origine de ambos mecanismos ${ }^{3}$. Cosa bien distinta es que en la aceptación de esa

2 Esta afirmación debe matizarse para hacer alusión al artículo 220 del TCEE (referido al reconocimiento y la ejecución recíproca de las decisiones judiciales y extrajudiciales en materia civil) y, sobre todo, a la posterior introducción del artículo 100B en el Acta Única Europea. El artículo 100B pretendió positivizar el principio de reconocimiento mutuo con efecto automático en relación con las disposiciones nacionales no armonizadas, pero nunca llegó a aplicarse dada la complejidad del análisis comparado. Por otro lado, el artículo 100B se consideró un retroceso en relación con la jurisprudencia Cassis de Dijon, induciendo a la confusión entre el principio de reconocimiento mutuo y el principio de equivalencia (L. GonZÁLEZ VAQUÉ, 1997: 129; M. LóPEZ Escudero, 1993: 159 y ss.).

3 La jurisprudencia del Tribunal de Justicia [SSTJCE de 21 de junio de 1974 (C-2/74, Reyners) y de 3 de diciembre de 1974 (C-33/74, Binsbergen)] siempre ha mantenido la necesidad de que las Directivas a las que aludía el viejo artículo 57 fueran aprobadas para conseguir la progresiva supresión de restricciones discriminatorias a la libre circulación y para introducir en las legislaciones nacionales disposiciones que garantizasen el ejercicio efectivo de esas libertades (G. C. Rodríguez Iglesias, 1977: 83 y ss.; A. MenÉndez Menéndez, 1988: 135 y ss.). Esto no quiere decir que el artículo 57 no gozara de efecto directo. En ausencia de armonización, se seguía aplicando la jurisprudencia del TJCE en la materia, en virtud de la cual «la solicitud de una autorización por el Estado de destino para ejercer una profesión cuyo acceso esté subordinado, con arreglo a la normativa nacional, a la posesión de un diploma o aptitud profesional, deberá tener en cuenta los diplomas, certificados y otros títulos que el interesado haya adquirido con objeto de ejercer esta misma profesión en otro Estado miembro, procediendo a una comparación entre la capacidad acreditada por dichos diplomas y los conocimientos y aptitudes exigidos por las disposiciones nacionales» [STJCE de 7 de mayo de 1992 (C-104/91, Aguirre Newman, S.A.)]. Una vez analizada la equivalencia del grado de conocimientos y aptitudes, si del examen de esos requisitos se derivaba una equivalencia total, debían reconocerse automáticamente las cualificaciones profesionales obtenidas en origen, mientras que si la equivalencia no era plena, el Estado de acogida estaba facultado para exi- 
complementariedad haya tenido mucha más trascendencia la adopción por la Comisión Europea de la estrategia regulativa conocida como Nuevo Enfoque 4 .

Una tercera consideración que pone de relieve aquel precepto es que el principio de reconocimiento mutuo opera con naturalidad no sólo en ámbitos armonizados y no armonizados, sino también en relación con todas las libertades comunitarias, sin perjuicio de su diferente intensidad aplicativa. En todo caso se ha de admitir que la aplicación del principio es semejante, pues los principios que gobiernan su aplicación son y han sido siempre los mismos (equivalencia, confianza mutua, país de origen, cooperación y subsidiariedad $)^{5}$. Ahora bien, esto no puede servir para ocultar la existencia de matices que, no obstante, se van diluyendo con el tiempo. Por un lado, la distinción entre

gir al interesado una prueba o examen que demostrase sus conocimientos en la materia. En términos similares, las SSTJCE de 15 de octubre de 1987 (C-222/86, Heylens), de 7 de mayo de 1991 (C-340/89, Vlassopoulou) y de 7 de mayo de 1992 (C-104/91, Colegio Oficial de Agentes). Por tanto, los Estados miembros podían exigir la acreditación de ciertos conocimientos para ejercer una determinada profesión, siempre y cuando las medidas exigidas no fueran equivalentes a las ya exigidas en origen [STJCE de 28 de abril de 1977 (C-71/76, Thieffry)].

4 Comunicación Cassis de Dijon (DOCE de 3.10.1980, C-256) y Libro Blanco Completing the Internal Market (Milán, 28-29.6.1985) [COM (85) 310]. El Nuevo Enfoque ha llegado a inducir la creencia de que el reconocimiento mutuo sólo opera previa armonización, olvidando que el principio se consolida con Cassis de Dijon en ámbitos no armonizados y que esto mismo sigue sucediendo con naturalidad en la actualidad. Del mismo modo, tampoco se ha de equiparar equivalencia y armonización. En esa línea parecen expresarse C. PADRós y J. M. MACíAs (2014: 124 y ss.). El principio de equivalencia es una condición necesaria para generar la confianza mutua que constituye la premisa aplicativa del principio de reconocimiento mutuo. En este sentido, el Abogado General RUIZ-JARABO en sus Conclusiones a la STJCE de 11 de febrero de 2003, al señalar que «la creación de un espacio europeo común no puede ser alcanzada sin una recíproca confianza de los Estados miembros en sus sistemas jurídicos que da lugar a un reconocimiento mutuo de sus respectivos pronunciamientos... En efecto, dicho reconocimiento se basa en la idea de que, aun cuando un Estado no trate de manera igual o similar modo que otro Estado, los resultados son tales que se aceptan como equivalentes a los propios porque responden a los mismos principios y valores». E, igualmente, la STJCE de 22 de diciembre de 2010 (C-491/10 PPU, Aguirre Zarraga) cuando afirma que «la confianza mutua supone la convicción de que los distintos sistemas jurídicos nacionales de la Unión están en condiciones de proporcionar una protección equivalente y efectiva de determinados objetivos de interés general y de los derechos de los justiciables». Por tanto, el principio de equivalencia sobre el que se asienta la confianza mutua se sustenta sobre una presunción general en virtud de la cual los sistemas jurídicos de los Estados miembros se fundamentan en principios y valores semejantes. En buena lógica, esa equivalencia se fortalece con la armonización legislativa, pero también a través de la armonización tácita que ya el propio Libro Blanco de 1985 imputara a la perspectiva transnacional que las normas nacionales debían adoptar al fijar los niveles de protección para la fabricación y comercialización de productos. En otras palabras, hay equivalencia sin armonización, sin perjuicio de que ésta fortalezca esa equivalencia y contribuya al automatismo del reconocimiento mutuo.

5 Véase J. Agudo (2014: 138 y ss.). También sigue viva la confusión del principio de reconocimiento mutuo con el principio del país de origen. Sin embargo, la consustancialidad del principio de país de origen con el principio de reconocimiento mutuo (M. GARDEÑES, 1999: 185) se encuentra en el entendimiento original del principio como regla conflictual en el seno del Derecho internacional privado. El mejor análisis, en L. DE LucIA (2009). Una posición crítica, en T. DE LA QUADRA-SALCEDO (2010). 
reconocimiento automático/ámbitos armonizados versus reconocimiento condicionado/ámbitos no armonizados sólo puede admitirse en términos genéricos, pues la armonización tampoco es determinante de la automaticidad del reconocimiento. Aquí, la libertad afectada puede ser determinante de la imposición de condiciones. Por otro lado, con independencia del tipo de reconocimiento mutuo, la solución conflictual inherente al principio (principio del país de origen) se instala sobre un escenario de cooperación que va adquiriendo el protagonismo definitivo.

Esta precisión nos lleva ante la última de las consideraciones que cabe detraer del antiguo artículo 57 del Tratado de Roma, aunque aquí también debemos reconocer la trascendencia fundamental de la jurisprudencia Cassis de Dijon. La puntualización que queremos hacer ahora es que el principio de reconocimiento mutuo, desde los orígenes de las Comunidades Europeas, se constituyó como un principio ordenador de la actuación administrativa en el seno de la Comunidad. Como se acaba de expresar, la evolución del principio ha consolidado su vertiente cooperativa frente a la conflictual. De hecho, se puede afirmar que la verdadera dimensión jurídico-aplicativa del principio de reconocimiento mutuo es ser la expresión principial de la articulación cooperativa de la Administración del espacio europeo en el plano de las relaciones horizontales entre Estados miembros. En otras palabras, el principio de reconocimiento mutuo se consolida como mecanismo facilitador de la libre circulación en el mercado interior.

Es justamente en este contexto donde se observa con claridad la conexión entre la vertiente sustantiva del principio (la efectividad de las libertades básicas) con las consecuencias que tiene la aplicación del principio de reconocimiento mutuo en los aspectos organizativo-institucionales y procedimentales u operativos: el principio de reconocimiento mutuo es un principio que favorece la actividad económica y, por este motivo, se plasma en una Administración no burocrática, no entorpecedora y no duplicadora de esfuerzos y costes. Este punto de arranque permite entender la flexibilidad jurídica que implica la optimización del principio y su consecuente focalización en la existencia de procedimientos complejos (más o menos formalizados) que involucran a varias Administraciones nacionales, cuyo objeto es el reconocimiento de actos que gozarán por ello de eficacia supranacional y que, en todo caso, están orientados a dotar de plena efectividad a las libertades comunitarias.

En el presente estudio analizaremos cómo funciona el principio de reconocimiento mutuo en el ámbito de la libre circulación de profe- 
sionales. La elección material se basa en varios motivos. En primer lugar, debido a la íntima conexión de la libre circulación de profesionales con el principio de reconocimiento mutuo desde su viejo reconocimiento en el artículo 57 del Tratado de Roma. En segundo lugar, porque la libre circulación de profesionales es un magnífico ejemplo de la evolución del principio en los distintos temas apuntados. Tercero y último, porque debemos insistir en que este trabajo tiene como uno de sus objetos principales el análisis de los efectos del principio de reconocimiento mutuo en la organización y en el funcionamiento de las Administraciones y, desde esta perspectiva, la libre circulación de profesionales expresa bien esas consecuencias. En este sentido, sintéticamente podría decirse que la vertiente sustantiva en que se traduce todo el sistema de reconocimiento mutuo de cualificaciones profesionales se sustenta sobre una estructura formal fundamentada, principalmente, en procedimientos administrativos compuestos de tipo horizontal y, por ello, con participación de las distintas Administraciones nacionales. En cualquier caso, esto no excluye ni la existencia de procedimientos compuestos verticales top-down y bottom-up, ni tampoco la incorporación de elementos mixtos (horizontales o verticales) que pueden incidir de forma variable en la decisión final. Nos centraremos, no obstante, en las relaciones de tipo horizontal que caracterizan a la Administración del reconocimiento mutuo. Finalmente, como pondremos de relieve, esa perspectiva dinámica se completa con otra organizativoestructural, débil, eso sí, pero con una trascendencia finalista no menor.

Debemos señalar, por último, que no se pretende realizar un análisis exhaustivo de esta materia ${ }^{6}$. El recurso al reconocimiento de cualificaciones profesionales se utiliza metodológicamente como sector de referencia, con el fin de inducir consecuencias jurídicas que puedan ser luego trasladadas a otros ámbitos en los que el principio de reconocimiento mutuo tiene aplicación. Por este motivo, tras una breve exposición de los mecanismos de reconocimiento, el grueso del estudio se centrará en la identificación de esas consecuencias, para, en la última parte del trabajo, llevar a cabo esa extrapolación de conclusiones a la Ley de Garantía de la Unidad de Mercado.

\footnotetext{
${ }^{6}$ Para un estudio completo, E. M. Ares (2005: 91 y ss.) o G. VeSPERINI (2011: 29 y ss.).
} 


\section{ELEMENTOS ESTRUCTURALES Y RECONOCIMIENTO MUTUO}

\section{Procedimientos horizontales y actos transnacionales}

\section{A) El reconocimiento de cualificaciones profesionales}

La Directiva 2005/36/CE, de 7 de septiembre ${ }^{7}$, establece el régimen jurídico al que cualquier Estado miembro debe subordinar «el acceso a una profesión regulada o su ejercicio, en su territorio, a la posesión de determinadas cualificaciones profesionales» (art. 1) ${ }^{8}$. A tal efecto, continúa el artículo 1 de la Directiva, el Estado de acogida «reconocerá para el acceso a dicha profesión y su ejercicio las cualificaciones profesionales adquiridas en otro u otros Estados miembros» (Estado de origen) que permitan al titular de esas cualificaciones ejercer en él la misma profesión. Del artículo 1 de la Directiva trasluce ya tanto la vertiente formal-cooperativa en que se concreta el reconocimiento mutuo de títulos de formación, como la vertiente sustantiva que se concreta en el ejercicio de una libertad comunitaria. Respecto a la primera, la norma europea dedica buena parte de su articulado; en cuanto a la segunda, es la consecuencia inmediata del procedimiento de reconocimiento mutuo (arts. 1 y 2 de la Directiva), recogiéndose en toda su intensidad en el artículo 4.1, cuando establece que el reconocimiento de las cualificaciones profesionales por el Estado de acogida «permitirá al beneficiario acceder en ese Estado miembro a la misma profesión que

7 La Directiva refunde las tres Directivas generales precedentes en la materia (la Directiva 89/48, de 21 de diciembre de 1988; la Directiva 92/51, de 18 de junio, y la Directiva 1999/42, de 7 de junio), así como las Directivas sectoriales hasta entonces vigentes [derogadas desde el día 20 de octubre de 2007 (art. 62)]. La nueva Directiva no afecta a otras relativas al reconocimiento de cualificaciones profesionales con normativa específica (art. 2.3), como las Directivas relativas a la prestación de servicios por los abogados (Directiva 77/ 249/CEE, de 22 de marzo) y al establecimiento de los abogados (Directiva 98/5/CE, de 16 de febrero). Tampoco se ha visto afectada por la Directiva 2006/123, de 12 de septiembre, relativa a los servicios en el mercado interior. Como establece el artículo 3.1.d) de esta Directiva 2006/123, si surge un conflicto entre una disposición de la Directiva y una disposición de otro acto comunitario relativo a aspectos concretos relacionados con el acceso a la actividad de un servicio o su ejercicio en sectores concretos o en relación con profesiones concretas, «estas otras normas primarán y se aplicarán a esos sectores o profesiones concretos», citándose a continuación, entre otras, la Directiva 2005/36.

8 En cuanto al ámbito subjetivo de la Directiva, téngase en cuenta que, según el artículo 2.1, se refiere a «todos los nacionales de un Estado miembro, incluidos los miembros de las profesiones liberales», que pretendan ejercer una profesión regulada en un Estado miembro distinto de aquel en el que obtuvieron sus cualificaciones profesionales. Respecto al ámbito objetivo, la Directiva entiende por «profesión regulada» [art. 3.1.a)] «la actividad o conjunto de actividades profesionales cuyo acceso, ejercicio o una de las modalidades de ejercicio están subordinados de manera directa o indirecta, en virtud de disposiciones legales, reglamentarias o administrativas, a la posesión de determinadas cualificaciones profesionales». 
aquella para la que está cualificado en el Estado miembro de origen y ejercerla con los mismos derechos que los nacionales».

Los procedimientos de reconocimiento mutuo para el acceso a una profesión regulada y a su ejercicio se diferencian en función de la temporalidad y carácter ocasional de la prestación. En función de estos criterios, cabe distinguir entre el ejercicio de una profesión que se ejerce como manifestación de la libertad de prestación de servicios, o bien como el acceso a la práctica de una profesión en el Estado de acogida, manifestación de la libertad de establecimiento. El artículo 5.2 de la Directiva identifica el primer supuesto, entendiendo que las previsiones de la Directiva relativas a la libre prestación de servicios son aplicables «únicamente» cuando «el prestador se desplace al territorio del Estado miembro de acogida para ejercer, de manera temporal u ocasional», una profesión que exija una cualificación profesional ${ }^{9}$.

\section{a) Actividades profesionales y libre prestación de servicios}

En el ámbito del ejercicio de la libre prestación de servicios para el ejercicio de profesiones reguladas, la lógica mueve a entender que el reconocimiento mutuo debería ser tendencialmente automático. Esto mismo es lo que se deduce de la Directiva, sin perjuicio de que la prestación del servicio pueda quedar sujeta a una eventual comprobación por parte del Estado de acogida en los términos del artículo $5.1^{10}$. Sin embargo, frente a esta premisa, la automaticidad del reconocimiento se ve condicionada en otros supuestos que habilitan una intervención in crescendo del Estado de acogida.

Un primer escalón básico de intervención se prevé en el artículo 7, donde se regula la declaración previa «en caso de desplazamiento del prestador». Según este precepto, los Estados miembros pueden imponer que el prestador presente, "por cualquier medio», una declaración previa cuando se desplace por primera vez ${ }^{11}$ que detalle los medios de ga-

9 El precepto continúa señalando que «el carácter temporal y ocasional de la prestación de servicios se evaluará en cada caso por separado, atendiendo en particular, a la duración de la propia prestación, su frecuencia, su periodicidad y su continuidad».

10 Según el artículo 5.1, los Estados miembros no pueden restringir, por razones de cualificación profesional, la prestación de servicios en otro Estado: «a) si el prestador está legalmente establecido en un Estado miembro para ejercer en él la misma profesión, y b) en caso de desplazamiento del prestador, si ha ejercido dicha profesión durante dos años como mínimo en el curso de los diez años anteriores a la prestación en el Estado miembro de establecimiento, cuando la profesión no esté regulada en el mismo». La condición de los dos años de práctica no es aplicable en caso de profesiones reguladas.

11 Renovable anualmente, de ser reiterada la prestación. 
rantía de seguros o similares de protección personal o colectiva en relación con la responsabilidad profesional ${ }^{12}$. Esto no excluye, de acuerdo con el artículo 7.2, que los Estados miembros puedan exigir, además, ya en el primer desplazamiento, ya en virtud de cambios sobrevenidos en la documentación requerida, documentación adicional ${ }^{13}$ cuya comprobación implica un condicionamiento mayor del reconocimiento.

Las mayores injerencias del Estado de acogida se prevén en el artículo 7.4. Hay que aclarar que esta posibilidad no es aplicable a las profesiones armonizadas, ya que éstas podrán ser ejercidas, como mucho, sujetas a la verificación documental que prevé el artículo 7.2. Para el resto de profesiones reguladas, la autoridad del Estado de acogida puede proceder a una verificación de las cualificaciones profesionales del prestador antes de la primera prestación de servicios ${ }^{14}$. Téngase en cuenta, además, que esta verificación únicamente será posible con el fin de evitar daños graves a la salud o la seguridad del destinatario del servicio por falta de cualificación profesional del prestador del servicio. En estas circunstancias, y en un plazo máximo de un mes desde la recepción de la declaración y de los documentos que la acompañen, la autoridad competente ha de comunicar al prestador de servicios su decisión de verificar sus cualificaciones. En caso de que dicha verificación pusiera de relieve una diferencia sustancial entre las cualificaciones profesionales del prestador y la formación exigida en el Estado de acogida, se deberá ofrecer al prestador la posibilidad de demostrar que ha adquirido tales conocimientos y competencias mediante una "prue-

12 El Cdo. 7. ${ }^{\circ}$ de la Directiva aclara que el Estado de acogida puede, "en caso necesario», establecer requisitos para la declaración que «no deben representar una carga desproporcionada para los prestadores de servicios ni obstaculizar o hacer menos interesante el ejercicio de la libertad de prestar servicios».

13 Se refiere a los documentos acreditativos de la nacionalidad, del certificado de establecimiento legal en el Estado de origen, del certificado de no estar incurso en prohibición que le impida ejercer su profesión, de los títulos relativos a las cualificaciones profesionales, entre otros. En este sentido, se ha de recalcar que el artículo 8.1 establece un deber de cooperación interadministrativo que facilita que las autoridades del Estado de acogida puedan solicitar para cada prestación, a las autoridades competentes del Estado de origen, toda información pertinente relativa a la legalidad del establecimiento de la actividad profesional y a la buena conducta del prestador, así como a la inexistencia de sanción de carácter profesional.

14 Como señala el Cdo. $17 .^{\circ}$ de la Directiva, esta medida debe ser proporcionada y tener en cuenta la experiencia profesional del solicitante. En este sentido, la STJUE de 18 de noviembre de 2011 (C-458/08, Comisión v. Portugal) condenó a Portugal por el incumplimiento de la Directiva 2005/36, "al exigir que las empresas de construcción establecidas en otro Estado miembro cumplan la totalidad de los requisitos a los que el régimen nacional, en particular el Decreto ley n. ${ }^{\circ}$ 12/2004, supedita la obtención de una autorización para ejercer en Portugal una actividad en el sector de la construcción, dicho régimen excluye que se tengan en cuenta debidamente las obligaciones equivalentes que se imponen a estas empresas en el Estado miembro de establecimiento y las verificaciones ya efectuadas a este respecto por las autoridades de este último Estado miembro». 
ba de aptitud» ${ }^{15}$. Lo más relevante es que la prestación de servicio debe poder realizarse dentro del mes siguiente a la decisión adoptada; por este motivo, el silencio de la autoridad de acogida habilita a la prestación de la actividad (silencio positivo).

En cuanto al régimen jurídico al que se somete la prestación de servicios, y en correspondencia con el principio del país se origen, la actividad profesional se ejerce generalmente con base en el título, certificado o formación profesional obtenidos en el Estado de origen ${ }^{16}$. Sin embargo, ni ésta es una regla exclusiva ${ }^{17}$, ni cuando es aplicable el principio del país de origen supone un desplazamiento íntegro del ordenamiento de acogida, pues incluso en esos supuestos el ejercicio de la actividad queda sujeto a la normativa del Estado de acogida en materia de responsabilidad profesional y disciplinaria (art. 5.3). Por otro lado, y en sentido contrario, se comprende que, en atención al carácter temporal de la prestación, el artículo 6 de la Directiva prevea una serie de dispensas a favor de los prestadores de servicios, como la inscripción en colegios profesionales y en la seguridad social ${ }^{18}$.

\section{b) Actividad profesional y libertad de establecimiento}

El establecimiento en un Estado miembro para el ejercicio de una profesión regulada puede someterse a tres regímenes jurídicos en fun-

15 La prueba de aptitud es el control realizado exclusivamente sobre los conocimientos profesionales del solicitante, efectuado por las autoridades del Estado de acogida, que tiene por objeto apreciar la aptitud del solicitante para ejercer en dicho Estado una profesión regulada. En cuanto a las modalidades de la prueba de aptitud y su régimen jurídico, el artículo 3.1.h) de la Directiva.

16 En estos casos, el Estado de acogida puede solicitar al prestador que facilite al destinatario del servicio información relativa a la publicidad oficial de su actividad profesional, los datos de la autorización que le habilita al ejercicio de la profesión, su pertenencia a asociaciones profesionales, identificación fiscal e información sobre garantías y seguros (art. 9). La Directiva pretende aquí que el usuario o el paciente conozcan la específica cualificación del prestador y las particularidades que rigen la prestación.

17 Excepcionalmente, se prevé que el servicio pueda ser prestado al amparo de un título profesional del Estado de acogida en los supuestos de las profesiones armonizadas (art. 7.3). También en el caso de verificación de las cualificaciones profesionales para el ejercicio de profesiones relacionadas con la salud y la seguridad pública, distintas a las profesiones armonizadas, se prevé el ejercicio profesional con base en el título del Estado de acogida (art. 7.4.V).

18 En relación con la carga de colegiación, la STJUE de 12 de septiembre de 2013 (C-475/ 11, Kostas Konstantinides) afirma que el artículo 6.a) de la Directiva «no prescribe ni las normas de conducta ni los procedimientos disciplinarios a los que puede estar sujeto un prestador que se desplace al territorio del Estado miembro de acogida para ejercer su profesión de manera temporal y ocasional, sino que se limita a disponer que los Estados miembros podrán prever bien una inscripción temporal que se produzca automáticamente o una adhesión pro forma a una organización o un organismo profesionales, a fin de facilitar la aplicación de las disposiciones disciplinarias». 
ción de las cualificaciones profesionales que se pretendan reconocer: $\left.1 .^{\circ}\right)$ el reconocimiento de títulos de formación ${ }^{19}$ queda supeditado a la acreditación de tales cualificaciones (art. 13) ${ }^{20}$ y, lo más importante, al eventual cumplimiento de medidas compensatorias ${ }^{21}$ ( $\sin$ perjuicio de los efectos derivados de la implantación de «plataformas comunes ${ }^{22}$ );

19 Este supuesto tiene carácter residual. Es aplicable a todas las profesiones no cubiertas por los Capítulos II y III del Título III, sin perjuicio de su aplicación en algunos supuestos en que el solicitante no reúna, por motivos particulares y excepcionales, las condiciones exigidas (art. 10).

20 Es necesaria la acreditación de una cualificación profesional equivalente «al nivel inmediatamente anterior al exigido en el Estado de acogida». Esos niveles de cualificación son (art. 11): $1 .^{\circ}$ ) formación básica o primaria; $2 .^{\circ}$ ) formación secundaria; $3 .^{\circ}$ ) formación postsecundaria de un año; $4 .^{\circ}$ ) formación postsecundaria de entre un año y cuatro; y $5 .^{\circ}$ ) formación postsecundaria de más de cuatro años.

Este requisito puede quedar matizado en los términos del artículo $13.2 .^{\circ}$ y $3 .^{\circ}$, donde se prevén supuestos asimilables y se habilita el reconocimiento de la experiencia profesional y de certificados de competencia, para el caso de que se haya ejercido esa profesión en un Estado donde no se encontraba regulada.

21 El Estado de acogida, potestativamente, puede exigir al solicitante la realización de un período de prácticas de tres años como máximo o de una prueba de aptitud en los casos señalados en el artículo 13.1, referidos a supuestos en los que existe divergencia entre la formación adquirida en origen y la exigida en el Estado de acogida, ya por la duración de la formación, ya por las divergencias en las materias impartidas (por tratar de materias sustancialmente distintas, en los términos del artículo 14.4) o en la propia actividad regulada. Si el Estado de acogida optara por imponer estas medidas compensatorias, el solicitante gozará del derecho a elegir entre realizar el período de prácticas o la prueba de aptitud, sin perjuicio de que dicho derecho pueda ser excepcionado en las condiciones del artículo 14.2, o bien impuesto (en la forma que designe el Estado de acogida) en los casos del artículo 14.3.

El artículo 14.5 establece que el principio de proporcionalidad gobierna la aplicación de este precepto [en coherencia con la STJUE de 17 de abril de 2008 (C-197/06, Confederatie van Immobiliën-Beroepen van België VZW), dictada en aplicación de la Directiva 89/48]. De ello se deriva la obligación de los Estados miembros de comprobar los conocimientos adquiridos por el solicitante a lo largo de su experiencia profesional, a los efectos de determinar si pueden satisfacer las diferencias existentes en la formación. La STJUE de 19 de enero de 2006 (C-330/03, Colegio de Ingenieros de Caminos, Canales y Puertos), dictada bajo la vigencia de la Directiva 89/48, y luego la STJUE de 27 de junio de 2013 (C-575/11, Nasiopoulos) han reiterado que en los casos en que las diferencias entre los campos de actividad sean tan grandes que, en realidad, el solicitante debiera seguir una formación completa para poder ejercer las actividades para las que está cualificado en otro Estado miembro, uno de los criterios a considerar es si la actividad profesional que se desea ejercer «es o no objetivamente disociable del conjunto de las actividades que abarca la correspondiente profesión en dicho Estado, el extremo de si se puede ejercer tal actividad, en forma independiente o autónoma, en el Estado miembro en el que se haya obtenido la cualificación profesional de que se trate, es un indicio al respecto». El Tribunal considera que el efecto disuasorio que produce la exclusión de toda posibilidad de reconocimiento vulnera el artículo 49 del TFUE.

22 Las "plataformas comunes» (art. 15) son "un conjunto de criterios de cualificaciones profesionales idóneos para paliar las diferencias sustanciales que se hayan observado entre los requisitos de formación existentes en los distintos Estados miembros en relación con una profesión determinada». Para determinar esas diferencias, el artículo 15.1 prevé la comparación de la duración y contenidos de la formación en al menos dos tercios de los Estados miembros que incluyan a todos los que regulen dicha profesión. Los Estados miembros o las asociaciones $\mathrm{u}$ organismos profesionales representativos a escala nacional y europea presentarán a la Comisión las plataformas comunes. Para ello, la Comisión consultará a todos los Estados miembros y presentará un proyecto de medidas conforme al procedimiento regulado en el artículo 58.2 de la Directiva, siempre y cuando considere que la plataforma fa- 
$\left.2 .^{\circ}\right)$ el reconocimiento de experiencia profesional debe acreditarse con la prueba del ejercicio previo de dicha actividad en otro Estado miembro (art. 16); la clave está en las normas sobre cómputo de los períodos de experiencia profesional ${ }^{23}$; y $3 .^{\circ}$ ) el reconocimiento automático aplicable a profesiones armonizadas ${ }^{24}$; la regla general es que los Estados reconocerán los títulos que den acceso a esas actividades profesionales, siempre y cuando se ajusten a las condiciones mínimas de formación, otorgándoles, para el acceso a las actividades profesionales y su ejercicio, el mismo efecto en su territorio que a los títulos de formación que ese Estado miembro expide (art. 21) ${ }^{25}$. No obstante, como vamos a mostrar a continuación, el calificativo del reconocimiento como «automático» es relativo, aunque sí tiene una consecuencia determinante: la prohibición de imponer a los profesionales la carga de obtener o probar cualificaciones adicionales ${ }^{26}$.

Para estos tres supuestos, los artículos 50 y 51 regulan cómo se articula procedimentalmente la acreditación de las cualificaciones profesionales. En los tres niveles debe verificarse documentalmente la formación o experiencia del solicitante y autorizarse el ejercicio ${ }^{27}$, aunque

cilita el reconocimiento mutuo. Si las calificaciones profesionales del solicitante satisficieran los criterios fijados por la Comisión, se suspenderá la aplicación de las medidas compensatorias.

23 De conformidad con los artículos 17 (para las actividades de la Lista I del Anexo IV), 18 (para las actividades de la Lista II del Anexo IV) y 19 (para aquellas de la Lista III del Anexo IV).

${ }^{24}$ La Directiva establece en los artículos 24 y ss. la regulación mínima sobre los requisitos de formación de ciertas profesiones que coinciden con las que habían sido objeto de armonización desde los años setenta: médico con formación básica y médico especialista, de enfermero responsable de cuidados generales, de odontólogo, de odontólogo especialista, de veterinario, de farmacéutico y de arquitecto.

${ }_{25}$ Téngase en cuenta que todo lo dispuesto se entenderá sin perjuicio de los derechos adquiridos por los profesionales en los términos de los artículos 23 y concordantes de la Directiva.

${ }^{26}$ La STJUE de 30 de abril de 2014 (C-365/13, Ordre des architectes) señala que la Directiva 2005/36 «no deja ningún margen de apreciación a los Estados miembros», de modo que si un nacional de un Estado miembro es titular de uno de los títulos armonizados «debe poder ejercer la profesión (...) en otro Estado miembro sin que éste le pueda exigir obtener o probar que ha obtenido cualificaciones profesionales adicionales».

27 El establecimiento y acceso a la actividad quedan condicionados por los siguientes trámites: $\left.{ }^{\circ}{ }^{\circ}\right)$ solicitud acompañada, en su caso, según la decisión de cada Estado, de los documentos enumerados en el Anexo VII; $2^{\circ} .^{\circ}$ la autoridad competente del Estado de acogida acusará recibo del expediente del solicitante en el plazo de un mes desde su recepción y le informará sobre la falta de algún documento (art. 51.1); $3^{\circ}$ ) en casos de «duda justificada», el artículo 50.2. ${ }^{\circ}$ y $3 .^{\circ}$ confiere al Estado de acogida: a) la facultad de «exigir», dice la Directiva, a las autoridades del Estado de origen la confirmación de la autenticidad de un título, así como la confirmación sobre la posesión de las condiciones mínimas de formación; b) el «derecho de comprobación» de si un título de formación fue impartido por un centro legalmente reconocido, o bien de los derechos profesionales que ese título confiere; y $4 .^{\circ}$ ) resolución motivada dictada en el plazo de tres meses (eventualmente prorrogable uno más). El silencio administrativo no se regula expresamente, pero se deduce que es negativo, pues el artículo 51.3 dispone que contra la decisión expresa «o la ausencia de decisión en el plazo prescrito» se podrá interponer el correspondiente recurso jurisdiccional. 
sólo en el caso del reconocimiento de títulos de formación (primer supuesto) es posible (a decisión de cada Estado miembro) imponer medidas compensatorias. De esto se deduce, como ya hemos anticipado, que la automaticidad que prescribe el artículo 21 para las profesiones armonizadas es relativa, si se entiende por reconocimiento automático el que como mucho exige una verificación documental sin que intermedie, por tanto, una decisión administrativa en el país de acogida que otorgue plena eficacia al acto de origen.

Para terminar, quienes obtengan la autorización del Estado de acogida podrán ejercer la actividad con base en el título de origen (art. 54), mostrando en toda su intensidad la trascendencia del principio del país de origen. Ahora bien, esta regla tiene importantes excepciones $^{28}$ que condicionan de forma consecuente esa afirmación.

B) El principio de reconocimiento mutuo como principio ordenador de procedimientos complejos: una Administración funcionalmente integrada

La programación normativa de las Administraciones nacionales en materia de reconocimiento de cualificaciones profesionales que lleva a cabo la Directiva 2005/36 muestra que el principio de reconocimiento mutuo tiene una función conectiva: de (1) la aplicación de la normativa (en materia de cualificaciones profesionales) por la Administración del Estado de origen en un caso concreto y, por tanto, para declarar una situación jurídica activa (otorgamiento del título correspondiente), con (2) la no aplicación plena de una normativa equivalente en el Estado de acogida y el consecuente reconocimiento de la situación jurídica nacida en el país de origen, otorgándole una eficacia similar a la que podría haber declarado la Administración de acogida

28 El artículo 52.1 dispone que los nacionales de los Estados que estén autorizados a ejercer una profesión regulada con arreglo al Título III utilizarán el título profesional del Estado de acogida para el caso de establecimiento en este segundo país. Además, si el título académico del Estado de origen pudiera confundirse en el Estado de acogida con un título que exija una formación complementaria no adquirida por el beneficiario, el artículo 54 faculta al Estado de acogida a exigir la utilización del título académico de origen. Por otro lado, si el título académico del Estado de origen pudiera confundirse en el Estado de acogida con un título que exija una formación complementaria no adquirida por el beneficiario, el artículo 54 faculta al Estado de acogida a exigir la utilización del título académico de origen.

Por último, si una profesión está regulada en el Estado de acogida por una asociación u organización (art. 3.2), sólo se podrá utilizar el título profesional así expedido si acreditan su pertenencia a esa asociación u organización. Si la condición de miembro se subordinase a la posesión de determinadas cualificaciones, se podrán exigir en las condiciones que prevé la Directiva (art. 52). 
conforme a su ordenamiento. Se puede deducir, por tanto, que una consecuencia lógica de la programación formal derivada del principio de reconocimiento mutuo es la articulación de la actuación administrativa mediante un iter procesal complejo y transnacional que ordena la «división del trabajo» o el reparto de funciones entre Administraciones nacionales ${ }^{29}$.

El principio de reconocimiento mutuo permite «nivelar» la divergencia existente entre la única tarea administrativa a llevar a cabo (reconocer el ejercicio y el acceso a una profesión) y la diversidad de competencias administrativas de las distintas Administraciones nacionales condicionadas a priori por el principio de territorialidad. En otras palabras, el principio de reconocimiento mutuo permite equilibrar mediante la programación procedimental ambas vertientes: nivela en un único iter procesal el ejercicio de competencias administrativas diversas en dos ámbitos nacionales distintos, con la existencia de una única «tarea administrativa». Esa nivelación competencias/tareas permite describir la actuación administrativa como única, esto es, como un continuo funcional (procedimiento complejo integrado funcionalmente).

¿Cómo se articula específicamente ese equilibrio de tareas y competencias? La premisa fundamental es que las Administraciones involucradas actúan con base en criterios cooperativos que, consecuentemente, no incorporan elementos de subordinación. Sin perjuicio de los matices, la estructura común sería la siguiente:

1. La Administración del país de origen dicta actos administrativos (expide un título...) que, potencialmente, tiene eficacia transnacional. La Administración actúa conforme a su ordenamiento en los términos matizados por el Derecho europeo.

2. ${ }^{\circ} \quad$ La eficacia transnacional del acto se articula mediante la solicitud por parte de la persona que ostenta el título, ante la Administración del país de acogida, del reconocimiento del título expedido en origen. La actuación jurídica de la Administración de acogida queda condicionada por la elección del titular del derecho del país de acogida y por la consecuente eficacia del acto del país de origen.

3. ${ }^{\circ}$ El principio de reconocimiento mutuo prohíbe que la actuación de la Administración del país de acogida sea reproductora de la precedente en origen. Las funciones de la Administración del Estado de acogida son variables y, en función del condicionamiento del reconocimiento

29 Aluden a esta perspectiva S. NiCOLIN (2005: 215) y L. DE LUCIA (2009: 21 y ss.). 
(automático versus condicionado), se concretan en una serie modulada de facultades de supervisión, verificación e intervención en general:

- La Administración de acogida, actuando en nombre propio y por cuenta propia, verifica documentalmente/impone medidas compensatorias/autoriza, siempre condicionado por el respeto del principio de proporcionalidad. Esta conclusión es aplicable incluso cuando la intervención de la Administración de acogida es más intensa (profesiones reguladas no armonizadas y eventual prueba de aptitud), pues, por ejemplo, en estos casos se establece una presunción de carácter favorable al ejercicio de la actividad profesional, confiriendo carácter positivo al silencio administrativo. Paradójicamente, el silencio es negativo en el caso del reconocimiento del ejercicio de profesiones armonizadas donde el reconocimiento es calificado de automático, y ello justificado tanto por la estabilidad de la relación profesional, como por su íntima conexión con la salud y la seguridad.

- Por lo que se refiere a la Administración de origen, una vez solicitado el reconocimiento y desde el punto de vista funcional, su actuación es fundamentalmente de transmisión de información. El país de origen asiste informativamente al país de acogida en su labor verificadora. En esa función, la Administración del país de origen también actúa en nombre y por cuenta propia ${ }^{30}$.

- La función de "asistencia informativa» es recíproca. Se pueden identificar casos en los que la transmisión de información tiene sentido bidireccional, sin perjuicio de que predomina la asistencia desde el Estado de origen a petición de la Administración del Estado de acogida.

- En relación con esta función de asistencia cooperativa, en algún precepto de la Directiva 2005/36 se establecen, sin embargo, relaciones aparentemente de subordinación. En algún supuesto excepcional se prevé expresamente que la Administración del Estado de origen debe actuar en virtud de la orden dirigida por parte de la Administración del Estado de acogida (p. ej., art. 50.2 de la Directiva 2005/36 31 ). En estos casos parecería que

30 La cooperación se lleva a cabo sin estar sujeta a la dirección de la Administración asistida, es decir, la Administración asistente actúa en su propio nombre. Un análisis completo, en F. WETTNER (2011: 311).

31 El precepto regula la solicitud de autorización para el establecimiento y ejercicio de una profesión regulada y la facultad del Estado de acogida para exigir la documentación acreditativa correspondiente. En este contexto, el apartado 2. ${ }^{\circ}$ del artículo 50 establece que «en caso de duda justificada, el Estado miembro de acogida podrá exigir de las autoridades competentes 
la Directiva confiere una potestad para que la Administración de un Estado miembro ordene directamente a la de otro y que, por tanto, la segunda actúe por iniciativa de la Administración de acogida. La literalidad del precepto podría dar pie a entender que en estos casos la Administración requerida no actuaría por cuenta propia y que, en consecuencia, no podría negarse a cumplir con la petición. Sin embargo, en estos supuestos el contexto de la relación interadministrativa sigue siendo cooperativo y, por ello, ni se establece una relación de subordinación ni existe traslado alguno de competencias: nos encontramos ante dos Administraciones distintas que no forman parte de una Administración unitaria desde el punto de vista organizativo. Esta apreciación permite hacer hincapié en que no es posible trasladar a estos casos las características definitorias de categorías internas como la delegación administrativa. Debe entenderse, por tanto, que en casos como el indicado el Derecho Europeo reclama la máxima diligencia en un contexto de cooperación leal y, en consecuencia, las Administraciones deberán atender las peticiones de otros Estados, aunque podrán no cumplirlas cuando consideren que no concurren las circunstancias que habilitan la petición de información.

- En la Directiva 2005/36 se observan efectos bidireccionales en las interconexiones entre ordenamientos que no se limitan a la mera cooperación informativa. Por efecto del reconocimiento mutuo de las cualificaciones profesionales, los profesionales pueden ejercer su profesión con base en el título, certificado o formación profesional obtenidos de conformidad con la normativa del Estado de origen, o, según los casos, con base en el título del Estado de acogida. Ahora bien, y éste es el dato que ahora se quiere recalcar, en todo caso los profesionales se someten a la normativa disciplinaria del Estado de acogida, lo que puede dar lugar a actuaciones administrativas con efectos de regreso en origen.

La segunda consecuencia fundamental de estos procedimientos complejos es que la resolución que pone fin al procedimiento transnacional es, por tanto, variable en su contenido, pero en todo caso está

de otro Estado miembro una confirmación de la autenticidad de los títulos de formación expedidos en ese otro Estado miembro y, llegado el caso, una confirmación de que, para las profesiones previstas en el título III, capítulo III, de la presente Directiva, el beneficiario reúne las condiciones mínimas de formación...». 
dirigida a reconocer plena eficacia a un acto dictado en el país de origen (acto con eficacia transnacional ${ }^{32}$ ) al que, en su caso, podrá adherirse otro acto que, desde luego, no es sustitutivo del anterior, sino accesorio o complementario de éste, habilitando su plena supranacionalidad. La clave, por tanto, es que como principio que rompe la equivalencia entre eficacia y jurisdicción territorial de las decisiones administrativas, el reconocimiento mutuo fundamenta la eficacia supraterritorial de las actuaciones administrativas. Esto implica:

1. $\quad$ Desde el punto de vista de la Administración: la superación de la unilateralidad definitoria del acto administrativo, pues para la Administración de acogida el acto dictado en origen llega a ser, incluso, como si hubiera sido dictado por ella y, por este motivo, ha de gozar de la presunción de validez y de la eficacia que caracteriza a sus propios actos. Esto se observa con claridad cuando el ejercicio de la profesión se realiza con base en el título dictado en origen, pero también cuando la autorización de ejercicio «interioriza» el título obtenido de conformidad con la normativa del Estado de origen y legitima que la actividad se lleve a cabo al amparo del título profesional del Estado de acogida. En este sentido, el reconocimiento mutuo fundamenta la multilateralidad de los actos administrativos desde la perspectiva de la Administración competente (decisión multilateral).

2. ${ }^{\circ} \quad$ Desde el punto de vista del destinatario del acto: la multilateralidad de los actos administrativos permite entablar: a) relaciones jurídicas entre la Administración de origen y el destinatario del acto, así como de terceros con ambos (pacientes, clientes, usuarios...); y b) relaciones jurídicas entre la Administración de acogida y el destinatario del acto, así como con terceros. Es decir, la concepción del acto transnacional como un acto multilateral-subjetivo es la base para la constitución de relaciones jurídico-administrativas multilaterales, tanto desde el punto de vista del destinatario del acto, como desde la perspectiva de la Administración competente.

32 El autor de referencia en la materia sigue siendo M. RUFFERT (2011) y, en la doctrina española, R. BocANEgRa y J. GARcía (2008). La propuesta clasificatoria más conocida en la que se integran los actos transnacionales es la formulada por G. SYDOw, seguida por J.-P. ScHNEIDER (2007: 315), M. RufFERT (2008: 90) y A. KEESEN (2009: 27). 


\section{El principio de reconocimiento mutuo como principio directivo para la creación de una estructura organizativa (débil) de colaboración y asistencia}

La aplicación del principio de reconocimiento mutuo se basa, como ya hemos expuesto, en estructuras cooperativas articuladas mediante procedimientos complejos horizontales. No obstante, esa vertiente dinámica procedimental se complementa con la existencia de ciertos elementos organizativos que, en todo caso, tienen una relevancia accesoria o complementaria. Se pueden distinguir hasta tres tipos de mecanismos de esta naturaleza: $1^{\circ}$ ) la designación de autoridades competentes en cada Estado miembro (art. 56.3) y de un coordinador para el reconocimiento de las cualificaciones profesionales (art. 56.4);.$^{\circ}$ ) la creación del Comité de Reconocimiento de Cualificaciones Profesionales (art. 58); y 3..$^{\circ}$ la designación de puntos de contacto (art. 57) ${ }^{33}$.

La atención debe centrarse en los puntos de contacto ${ }^{34}$. Los puntos de contacto (regulados en el artículo 57 de la Directiva 2005/36) son un elemento común en la normativa armonizadora en el marco del principio de reconocimiento mutuo y del ejercicio de las libertades comunitarias en el seno del mercado interior. La designación de estos puntos de contacto suele recaer en unidades administrativas a las que se les confieren competencias de asistencia y gestión de información. La atención sobre estas unidades administrativas tiene que ver tanto con

33 El primero no merece mayor explicación. Sí merece la pena señalar que a los coordinadores para el reconocimiento de las cualificaciones profesionales les corresponde promover una aplicación uniforme de la Directiva y recopilar toda la información necesaria para su aplicación, para lo cual podrán solicitar ayuda de los puntos de contacto. Téngase en cuenta, además, que mediante Decisión de la Comisión 2007/172, de 19 de marzo, ha sido creado el Grupo de Coordinadores para el Reconocimiento de las Cualificaciones Profesionales, con el fin de prestar asesoramiento especializado a la Comisión.

La creación del Comité de Reconocimiento de Cualificaciones Profesionales tampoco es algo original, pues es frecuente la creación de comités de asistencia similares. Sí merece la pena poner de relieve que este Comité, como otros, actúa con base en estructuras cooperativas en las que se integran representantes nacionales y europeos (que presiden el Comité) y que la toma de decisiones es articulada a través de procedimientos compuestos (comitología) (art. 58.2).

34 La aplicación del reconocimiento mutuo no sólo genera estas soluciones organizativas. Por ejemplo, en el marco de la libre circulación de mercancías, el Reglamento 765/2008, de 9 de julio, establece un sistema de acreditación que garantiza la aceptación mutua del grado de competencia de los organismos de evaluación de la conformidad, complementando la Decisión 768/2008/CE, de 9 de julio, que establece el marco común para la comercialización de los productos. Los organismos de evaluación de la conformidad son entidades privadas acreditadas por los Estados miembros, para decidir sobre la conformidad de los productos con efectos comunitarios. Es decir, el sistema implica una institucionalización a través de la atribución de funciones públicas a entidades privadas (H. C. RöHL, 2011: 211). 
la relevancia de sus funciones desde una perspectiva finalista, como con su especial caracterización institucional. Vayamos por partes.

La extensión aplicativa del reconocimiento mutuo a todas las libertades comunitarias ha ido acompañada de una diferente fuerza aplicativa del principio en función de la intensidad y estabilidad que define a la relación jurídica que nace con la posición jurídica activa inherente a la propia libertad. La afirmación de principio es que cuanto más intensa es esa relación (en términos de temporalidad), menos inmediata ha sido la afirmación del principio de reconocimiento mutuo. Por otro lado, no se puede desconocer que las libertades comunitarias son derechos con una orientación economicista que demandan medios para la generación de confianza y el favorecimiento de los intercambios. Ambas consideraciones han tenido consecuencias en relación con el tipo de Administración que estructura la unión administrativa del mercado interior:

1. ${ }^{\text {a }}$ La Administración ejecutiva de reconocimiento mutuo no es unitaria, sino netamente cooperativa e integrada funcionalmente: tratándose de derechos que son reconocidos con una incidencia temporal muchas veces limitada, esto induce a comprender la inadecuación, en términos de eficacia, y la innecesariedad, en términos de eficiencia, de sustituir la actuación administrativa nacional por otra supranacional y unitaria ${ }^{35}$. Por tanto, la Administración designada para cumplir con las exigencias derivadas del principio de reconocimiento mutuo es una Administración de intervención, autorizatoria en origen y de verificación más o menos intensa en destino; aquí podemos hablar de una Administración concebida para el control de los ciudadanos, aunque la articulación general del procedimiento esté orientada a favorecer el ejercicio de las libertades comunitarias.

2. ${ }^{a} \quad$ Frente a esa Administración ejecutiva, y con una relevancia menor, la novedad se encuentra en la creación de una Administración no ejecutiva y «de colaboración y asistencia»: se trata de una Administración específicamente designada para lograr la maximización de la eficacia del Derecho Europeo y, por este motivo, exclusivamente destinada a colaborar en la salvaguardia del cumplimiento del ordenamiento comunitario en lo correspondiente a la garantía de las libertades comunitarias. Tampoco es una Administración unitaria, pero sí es una Administración que, aunque pueda formar parte organizativamente de

35 Esta afirmación tendría que ser matizada a la vista de los efectos que la integración europea tiene en la desestatalización de las Administraciones públicas nacionales. Véase J. Agudo (2014). 
la Administración nacional, funcionalmente se desvincula de la misma y conecta sus atribuciones con el cumplimiento del Derecho europeo, por parte de su propio Estado, a requerimiento de la Comisión Europea o de los ciudadanos. El punto de contacto es una unidad administrativa de conexión entre el ciudadano, la Administración nacional (y, por extensión, el resto de Administraciones estatales) y la Comisión Europea.

Esas estructuras organizativas tienen como función facilitar el ejercicio de los derechos reconocidos por el Derecho Europeo, es decir, constituyen una incipiente Administración no decisional, específicamente dirigida a favorecer el ejercicio de las libertades comunitarias mediante la transmisión de información, la asistencia al ciudadano y la resolución de conflictos mediante mecanismos tendencialmente autocompositivos (Red SOLVIT ${ }^{36}$ ). En fin, una Administración generadora de la confianza que precisan los operadores económicos y facilitadora del ejercicio efectivo y fructífero de las libertades comunitarias, cuyas funciones son específicas y distintas de las que puedan corresponder a las autoridades competentes en cada Estado miembro designadas para ejecutar la Directiva.

3. ${ }^{a} \quad$ Desde el plano estrictamente organizativo, el análisis de esa Administración de colaboración y asistencia es bastante poco revelador, pues, como ya hemos señalado, el Derecho Europeo respeta la autonomía institucional de los Estados miembros para crear estas estructuras organizativas. Es decir, a diferencia de otros muchos sectores, en relación con los puntos de contacto no se exige que sean constituidos como personas jurídicas autónomas y con independencia funcional o que se creen órganos independientes. Las exigencias de tipo estructural-organizativo son mucho más livianas y su interés se limita a la perspectiva funcional. En primer lugar, porque esta Administración quiebra la concepción de la Administración como una organización constituida desde arriba, esto es, para el ejercicio de poder público sobre los ciudadanos. En segundo lugar, y consecuentemente, porque las funciones que posee son concebidas, en buena medida, desde el ciu-

36 SOLVIT es una red que, mediante el establecimiento de un sistema que podríamos calificar como de cercano a la "conciliación», permite que a través de puntos de contacto designados por los Estados miembros se pueda reclamar el cumplimiento del Derecho Europeo y la salvaguardia de las libertades comunitarias ante una eventual vulneración en otro Estado de la Unión Europea. La libre circulación de profesionales es, desde el plano estrictamente cuantitativo, la materia con más asuntos sometidos a SOLVIT después de los concernientes a la seguridad social (informe Making the Single Market Deliver, Annual governance check-up 2011). La red se ordena por la Recomendación de la Comisión, de 7 de diciembre de 2001, sobre los principios para la utilización de SOLVIT [Red de Resolución de Problemas en el Mercado Interior (2001/893/CE)]. Sobre la Red SOLVIT, véanse M. LotTINI (2010 y 2014), L. MusSELLi (2012) y D.-U. GALETTA (2014). 
dadano, esto es, es una Administración para ayudar al ciudadano a ejercer sus derechos. Tercero, porque es una Administración cuyas funciones se articulan, fundamentalmente, a través de la gestión de información ya sea para reportar de forma general sobre el estado de cumplimiento del Derecho Europeo y, por ello, del grado de protección de las libertades comunitarias, ya para asistir o mediar en el caso concreto. La idea clave es la protección a través de la información: una Administración asistencial como Administración que proporciona información como mecanismo para la salvaguarda de las libertades comunitarias.

4. ${ }^{\text {a }}$ La cuarta conclusión es que esa débil institucionalización que se deriva del principio de reconocimiento mutuo, precisamente por todo lo dicho hasta ahora, responde a criterios fundamentalmente económicos: la Administración del reconocimiento mutuo es la base de una Administración del mercado interior que debe generar la confianza necesaria para facilitar los intercambios económicos. Desde este punto de vista, uno de los datos que se pone de relieve como elemento que afecta al ejercicio de las libertades comunitarias es la dificultad de obtener información. Pues bien, el principio de reconocimiento mutuo contribuye a rebajar la carga de obtener una información completa, ya que el operador económico, el profesional, en definitiva, no tiene que cargar con el coste de conocer exhaustivamente el ordenamiento jurídico del país de acogida, en la medida en que el principio programa la actuación administrativa de modo que simplifica el acceso a la información mediante la creación de una Administración constituida ex profeso como fuente de información y asistencia. Con ello se compensan tanto la ausencia de apoyo corporativo ${ }^{37}$, como la debilidad inherente del ciudadano en situaciones de movilidad.

3. Conclusión: la vertiente formal del principio de reconocimiento mutuo gobierna de forma determinante la programación de la actuación administrativa

El principio de reconocimiento mutuo es un principio estructural articulador de las relaciones interadministrativas que conecta su opti-

37 De algún modo, podría decirse que esa Administración asistencial suple las funciones que la Administración corporativa cumple respecto de sus colegiados (art. 3.2 de la Directiva). Recuérdese, en este sentido, que, según la Directiva 2005/36, la colegiación puede quedar incluso dispensada. Por este motivo, careciendo el profesional de la protección y ayuda del Colegio Profesional, se comprende que esas funciones puedan ser suplidas mediante un entramado institucional de tipo asistencial. 
mización con la función programadora inherente a la capacidad directiva del Derecho Administrativo; concretamente, con una programación de tipo formal de las Administraciones nacionales. Dicho de otra manera, la programación de la conducta de las Administraciones nacionales en las relaciones horizontales gobernadas por el principio de reconocimiento mutuo se fundamenta en contenidos «infraestructurales» de tipo dinámico o procedimental y, más débilmente, de tipo organizativo-institucional.

No es excesivo decir que para la efectividad del principio adquiere una relevancia determinante el Derecho de organización como instrumento de dirección y programación de las funciones atribuidas a las Administraciones en relación con la efectividad de las libertades comunitarias. Se podría decir, por un lado, que el principio de reconocimiento mutuo inspira una estrategia regulativa cuya principal consecuencia es dotar de una relevancia fundamental al Derecho de organización y al procedimiento administrativo como instrumentos de programación de la actividad administrativa ${ }^{38}$. Por otro lado, debemos recordar que la programación de la actuación administrativa que se deriva del principio de reconocimiento mutuo expresa que lo organizativo/procedimental no sólo condiciona lo operativo o funcional, es decir, determina cómo deben articularse las funciones de las Administraciones involucradas para lograr los objetivos establecidos, sino también es determinante de la consecución de los objetivos de naturaleza sustantiva.

Se puede afirmar, en definitiva, que el principio de reconocimiento mutuo dirige la programación normativa hacia normas de conducta netamente formales y, por tanto, el peso de la densidad normativa en que se concreta el principio goza de esa caracterización formal, aunque orientada finalísticamente a objetivos netamente sustantivos (la salvaguardia y efectividad de las libertades comunitarias). Dicho de otro modo, se deduce del principio de reconocimiento mutuo que la densidad normativa de tipo sustantivo que ordena la optimización regulativa del principio es baja, en comparación con la de tipo formal. Ahora bien, cómo se ordenen los procesos de toma de decisiones es un dato determinante para lograr o no ese objetivo y, por tanto, para determinar si la libre circulación de profesionales es o no efectiva. De todo ello se deriva que la programación normativa que induce el principio de reconocimiento mutuo es fundamentalmente simplificadora de la actuación reguladora y administrativa y, en consecuencia, restrictiva de

38 Esto, no obstante, es común en el Derecho Europeo y en los Estados miembros, más allá del principio de reconocimiento mutuo (M. RUFFERT, 2008: 99; E. SCHMIDT-AsSMANN, 2011a: 13). 
cualquier carga o límite no justificado en términos de adecuación y necesidad (proporcionalidad) ${ }^{39}$.

El protagonismo en la programación administrativa de normas de conducta de tipo formal podría parecer contradictorio con la idea de que la aplicación del principio de reconocimiento mutuo evoluciona hacia una tendencial automaticidad. Si el reconocimiento ha de ser automático, podría decirse que esa consecuencia es incompatible con la regulación de un procedimiento administrativo que pudiera entorpecer la plenitud del reconocimiento de la actuación del país de origen. Aquí se deben reiterar varias consideraciones. Primera, como insistiremos más adelante, lo que exige el principio de reconocimiento mutuo es lograr el ejercicio efectivo de las libertades comunitarias conforme al principio del país de origen, pero ello no exime de cualquier actuación administrativa de control sobre aquella actuación administrativa. En otras palabras, el control en el país de acogida condiciona la eficacia plena de la actuación foránea. Segundo, consecuentemente, la representación comúnmente admitida de que la aplicación del reconocimiento mutuo nos lleva a escenarios de reconocimiento automático de actos transnacionales one-stop, es decir, sin intervención administrativa alguna en el Estado de acogida, no es correcta si es aplicada de forma general. Lo que veda el principio de reconocimiento mutuo son las actuaciones administrativas burocratizadas, duplicadas y, en general, que impliquen cargas desproporcionadas, que impidan otorgar eficacia supraterritorial a la actuación en origen.

En muchos ámbitos, como el de la libre circulación de profesionales, el reconocimiento regulado por las normas europeas, por mucho

39 Esta función programadora es implícita al principio de reconocimiento mutuo y no depende necesariamente de que el principio se aplique previa armonización. Es decir, aun en los ámbitos no armonizados, el principio se traduce en una programación dinámica (procedimental) de la actuación administrativa regida por los criterios indicados. La menor formalización de esos procedimientos no empece para admitir que la actuación administrativa deba regirse por criterios homogéneos, sin perjuicio de que esto se haga más palpable en los ámbitos armonizados. La libre circulación de profesionales es un buen ejemplo. En primer lugar, porque el artículo 57 del Tratado de Roma ha gozado de eficacia directa, de modo que su aplicación antes de la armonización del reconocimiento de cualificaciones profesionales fue mantenida por una nutrida jurisprudencia del Tribunal de Justicia que luego fue clave para la armonización de legislaciones. Segundo, porque, producida esa armonización, el reconocimiento de certificados, diplomas y títulos se basa en parámetros de distribución de la actuación administrativa parecidos, con independencia de que la profesión sea una de las que la propia Directiva califica como armonizadas [la STJUE de 27 de junio de 2013 (C-575/11, Nasiopoulos), es un buen ejemplo]. Los matices atienden a los condicionamientos del reconocimiento de la actuación de origen y a su consiguiente automaticidad y, por tanto, al protagonismo que se otorga a la actuación administrativa de acogida. Aquí, la línea divisoria entre reconocimiento automático y no automático o condicionado es cada vez más difusa, sin perjuicio de admitir una tendencial automaticidad. 
que se autodenomine "automático», no es exactamente un reconocimiento mecánico de una decisión única dictada por la Administración competente del país de origen. La realidad es que en el marco de la libre circulación de profesionales casi siempre existe una tarea que corresponde a la Administración de acogida consistente, en intensidad creciente, en la mera supervisión y la verificación documental o la intervención y autorización mediante actos que no son sustitutivos del dictado en origen, pero que sí habilitan su eficacia en destino. En definitiva, a pesar de la tendencial automaticidad del reconocimiento mutuo, sobre todo en ámbitos armonizados, y no obstante la literalidad utilizada por la propia Directiva 2005/36 (reconocimiento automático de las profesiones armonizadas), no se puede decir que el reconocimiento sea, en puridad, no condicionado, esto es, que no requiera ninguna actuación «receptora» por la Administración del Estado de acogida. Hay, siendo más exactos, una escala de «automaticidad», como hay tipos de reconocimiento mutuo. En esto también tiene mucho que ver la libertad cuya efectividad se ampara: mayor rigidez cuanto más estable es la relación final con el Estado de $\operatorname{acogida}^{40}$, lo que explica que el es-

40 Entre los ámbitos armonizados que afectan a libertades con una estabilidad temporal en principio baja y en los que el reconocimiento mutuo es automático en sentido estricto cabría citar, por ejemplo, el reconocimiento de las licencias de empresa ferroviaria reguladas en el artículo 23.1 de la Directiva 2012/34/UE, de 21 de noviembre, por la que se establece un espacio ferroviario europeo único, y según el cual «la validez de una licencia se extenderá al conjunto del territorio de la Unión». Eso es todo.

También cabría citar la circulación de mercancías en ámbitos armonizados, aunque con algunos matices. El Nuevo Enfoque supuso la armonización de las exigencias esenciales relacionadas con la protección de la salud y la seguridad de los consumidores y trabajadores, aunque en otras ocasiones pudieran tener relación con la protección del medio ambiente. Las Directivas obligan a adoptar a los fabricantes un nivel de protección estándar para todos los productos que se fabriquen en los Estados miembros, aunque otorgan flexibilidad para elegir la forma en la que satisfacen tales obligaciones. Si se satisfacen esos requisitos, la consecuencia es la declaración de esos productos como conformes, pudiendo portar la marca CE. En este sentido, el Nuevo Enfoque implicó también depurar los mecanismos de evaluación de la conformidad (Enfoque Global). La Decisión 768/2008/CE, de 9 de julio, establece el marco común para la comercialización de los productos, fijando las directrices y procedimientos para la evaluación de la conformidad, entre los que el legislador puede elegir el más apropiado, destacando la marca CE y el certificado de conformidad para vehículos (COC). Ahora bien, excepcionalmente, si un Estado constatara que un producto puede generar riesgos, puede adoptar las medidas necesarias para retirar o prohibir la comercialización del producto. En tal caso, podrá restringirse temporalmente la circulación del producto, aunque vaya acompañado de un certificado de conformidad. Para ello, el Estado miembro deberá informar a la Comisión justificando los motivos de su decisión; la Comisión consultará a los Estados miembros implicados y al Comité Permanente. Si se considera justificada una acción, la Comisión informará a los Estados para que prohíban la comercialización.

En relación con el reconocimiento en ámbitos no armonizados, el grado de automatismo en el reconocimiento no es necesariamente bajo. Respecto a la libre circulación de mercancías, el Reglamento 764/2008, de 9 de julio, establece los procedimientos que los Estados miembros tienen que satisfacer cuando pretendan no aplicar la regla del principio de reconocimiento mutuo en virtud de una norma técnica nacional. Estos procedimientos son co- 
tablecimiento de profesionales titulados en alguna de las profesiones armonizadas no pueda calificarse en puridad como un reconocimiento incondicionado.

En conclusión, todas estas consideraciones permiten finalizar señalando que el principio de reconocimiento mutuo, como principio que ordena relaciones cooperativas entre las Administraciones nacionales, se concreta en una programación netamente procedimental y variable desde el punto de vista de su densidad, medida en un mayor o menor control en el país de acogida.

III. EL PRINCIPIO DE RECONOCIMIENTO MUTUO Y LA CONSTRUCCIÓN DE UN DERECHO ADMINISTRATIVO EUROPEO EX PARTE CIVIUM

\section{La programación formal al servicio de los objetivos sustantivos}

El principio de reconocimiento mutuo es un principio estructural del Derecho Europeo desde sus orígenes, integrado como propio del ius publicum europeum. Así lo demuestra su incorporación en el artículo 57 del Tratado de Roma, pero también lo corroboran los esfuerzos del Tribunal de Justicia y de la Comisión Europea en su expansión y consolidación. El carácter estructural del principio de reconocimiento mutuo le caracteriza como un principio general del Derecho Europeo que se articula formalmente, pero que está vinculado teleológicamente a la efectividad de las libertades fundamentales que ordenan las relaciones entre ciudadanos europeos, instituciones comunitarias y Estados miembros ${ }^{41}$. Este dato permite entender que la programación formal implícita en el principio de reconocimiento mutuo se alza al servicio de objetivos sustantivos y que, con mayor relevancia, se manifiesta como elemento determinante de la satisfacción de tales objetivos. Es cierto que el ejercicio de las libertades de circulación (en nuestro caso de profe-

nocidos como procedimientos de simple información y se dividen en tres fases. La primera es la fase de recabar información previa. La segunda es la fase de aviso al agente económico, en la que las autoridades nacionales están obligadas a informar motivadamente y por escrito de su intención de adoptar una decisión que impida el reconocimiento del producto. La última fase es la fase de notificación motivada a la Comisión y a los agentes económicos de la decisión. La omisión de notificación o el transcurso de los plazos establecidos para dictar la resolución suponen la plena eficacia del reconocimiento mutuo. Se ha de añadir que el artículo 5 del Reglamento dispone que en ningún caso las autoridades nacionales podrán impedir el reconocimiento de los productos avalados por un organismo de evaluación de la conformidad, de acuerdo con el Reglamento 765/2008, de 9 de julio.

41 La vertiente sustantiva del principio ha sido especialmente recalcada por L. DE LUCIA (2009) 
sionales) se podría llegar a conseguir mediante mecanismos de intervención tradicionales, pero lo que no podría lograrse con esa forma de actuación administrativa es un ejercicio sin barreras burocráticas ni temporales desproporcionadas y, por consiguiente, desincentivadoras, limitadoras y entorpecedoras de la efectividad real de las libertades comunitarias $^{42}$.

Los fines sustantivos, por tanto, condicionan y predeterminan la articulación organizativo-procedimental de las relaciones horizontales transnacionales que ordena el principio de reconocimiento mutuo. Para ser exactos, habría que decir que el principio de reconocimiento mutuo, en su vertiente formal, gobierna la programación administrativa en términos cooperativos, simplificadores y facilitadores del reconocimiento y del ejercicio del derecho a la libre circulación. Es decir, en el plano formal, el principio es una manifestación del principio de intervención mínima y, por ello, del principio favor libertatis. La clave se encuentra en que son los fines sustantivos perseguidos los que imponen ese resultado, en lo que podría calificarse como una manifestación ex parte civium o bottom-up del Derecho Administrativo Europeo ${ }^{43}$.

Esta premisa condiciona de forma definitiva el tipo de relaciones interadministrativas que se entablan entre los Estados miembros. En primer lugar, la consolidación del principio y su naturalización como principio rector de la Administración del mercado interior han permitido que esas relaciones, siendo in origine relaciones entre Estados soberanos bajo su consideración natural como relaciones sometidas al Derecho Internacional, se hayan normalizado como relaciones interadministrativas de Derecho Europeo y para el cumplimiento del Derecho Europeo. En otras palabras, el reconocimiento mutuo se ha afianzado como un principio relacional dentro de la esfera del ius publicum europeum que implica directamente a las Administraciones designadas para cumplir con el Derecho Europeo: el principio de reconocimiento mutuo dirige relaciones interadministrativas transnacionales, no relaciones gubernamentales internacionales ${ }^{44}$. Sólo esta so-

42 La eliminación de efectos disuasorios se reafirma en la STJUE de 27 de junio de 2013 (C-575/11, Nasiopoulos), reconociendo los efectos de esa naturaleza de una legislación nacional que excluye el acceso parcial a una profesión regulada en el Estado de acogida, a un nacional de ese mismo Estado que había obtenido en otro Estado miembro un título que le autorizaba a ejercer una parte de las actividades que abarca la profesión regulada en el Estado de acogida.

43 Esta afirmación se vincula con el planteamiento que A. vON BogDANDY (2013) realiza de la configuración de la ciencia jurídico-administrativa en el espacio jurídico europeo desde la perspectiva del ciudadano. En esa dirección también, algunas precisiones en J.-P. ScHENEIDER (2008: 44 y ss.).

44 R. SchÜTZE (2010: 1410) se muestra contrario a otorgar carácter general a la ejecución pro unione que define a las actuaciones transnacionales, en virtud de la preferencia tradicional 
lución es compatible con la automaticidad (tendencial y relativa, como ya hemos insistido, en el marco de la libre circulación de profesionales) que implica la aplicación del principio de reconocimiento mutuo, y sólo esa solución eleva al principio de reconocimiento mutuo como uno de los principios articuladores de la unión administrativa del mercado interior, entendida como un espacio administrativo común no unitario desde el punto de vista institucional u organizativo, pero sí integrado funcionalmente y, por ello, dirigido a cumplir con el Derecho Europeo mediante la garantía de las libertades comunitarias.

La consecuencia inmediata de los términos que caracterizan a las relaciones horizontales transnacionales afecta a la programación/ ordenación de los procedimientos administrativos que permiten articular la consecución del objetivo sustantivo. Por este motivo, se comprende que el principio de reconocimiento mutuo sólo pueda optimizarse mediante la mínima intervención posible del Estado de acogida, otorgando eficacia a la actuación administrativa en origen y evitando la superposición de controles administrativos ${ }^{45}$. Por último, como la actuación de las Administraciones nacionales en pro de garantizar el ejercicio de las libertades básicas está sometida al Derecho Europeo, permite concebir a esas Administraciones como una Administración funcionalmente europea. Esto tiene consecuencias en las relaciones que esas Administraciones entablan con los ciudadanos, por la sencilla razón de que esas relaciones no pueden concebirse como meras relaciones jurídicas domésticas. Por ese mismo motivo, su actuación queda plenamente sujeta a los parámetros derivados del derecho a la buena administración ${ }^{46}$.

por la ejecución indirecta. Sin embargo, la evolución del Derecho Europeo demostraría lo contrario (J. Agudo, 2014).

45 Para G. CORSO (2007: 131), «produce moltre una drástica riduzione dell'attività amministrativa di controllo sul presupposto della unicità del controllo», añadiendo que es «un potente deflettore dell'attività amministrativa, nel senso della forte riduzione dei procedimenti autorizzatori...».

$46 \mathrm{El}$ artículo 41.1 de la CDFUE reconoce el principio de buena administración, pero lo refiere a «las instituciones y órganos de la Unión». Ahora bien, el artículo 51 de la Carta establece que las disposiciones de la misma están dirigidas «a las instituciones y órganos de la Unión, respetando el principio de subsidiariedad, así como a los Estados miembros únicamente cuando apliquen el Derecho de la Unión». No se puede ocultar la contradicción existente entre ambos preceptos al designar a sus destinatarios, aunque lo más razonable ha de ser mantener una aplicación general del artículo 51 (J. A. FuENTETAJA, 2008: 143; E. NiETO e I. Martín, 2010: 118 y ss.; J. Agudo, 2013: 75). 
2. Titularidad de derechos, elección del Derecho aplicable y sometimiento a la supralegalidad europea

La construcción ex parte civium del Derecho Administrativo Europeo se sustenta y parte de la garantía de las libertades comunitarias. Las libertades europeas constituyen valores comunes que se agregan a los deducibles de las tradiciones jurídicas comunes de los Estados miembros y que, conjuntamente, conforman el marco principial y valorativo de todo un ordenamiento común. Desde el plano del titular de esos derechos, el concepto de ciudadanía europea sintetiza la configuración de sujetos titulares de derechos europeos con eficacia transnacional (arts. 20.2 y correlativos del TFUE y de la CDFUE ${ }^{47}$ ). El ciudadano europeo es, por tanto, titular de los derechos de libre circulación que sólo son recognoscibles como tales en un contexto europeo y, por ello, su ámbito territorial de referimiento ha de ser necesariamente el europeo $^{48}$, ya que esa consecuencia es parte de su contenido esencial (art. 52.2 de la CDFUE). ¿Cómo se puede interpretar, si no, el artículo 15.2 de la CDFUE cuando dispone que «todo ciudadano de la Unión tiene la libertad de buscar un empleo, de trabajar, de establecerse o de prestar servicios en cualquier Estado miembro»? En otras palabras, esos derechos gozan de una inherente eficacia general no compartimentable en un correlato con la noción de jurisdicción territorial.

Aparte de las consecuencias de este presupuesto en la programación formal de la actuación administrativa (adaptación finalista), se deben destacar las que produce en el sometimiento a la legalidad condicionada por la elección, imputable al titular de los derechos de libre circulación, del Derecho aplicable. Sobre la elección del Derecho aplicable volveremos más adelante, pero ahora se ha de apuntar que, en términos aplicativo/temporales, la elección del Derecho aplicable es una premisa que condiciona la aplicación del Derecho en el contexto cooperativo del reconocimiento mutuo:

47 El artículo 15 de la CDFUE reconoce la libertad profesional y, en su apartado 2. ${ }^{\circ}$, la libre circulación de los trabajadores, la libertad de establecimiento y la libre prestación de servicios. El mismo artículo 15.2 identifica como titulares de esos derechos a «todos los ciudadanos europeos».

48 Esto conecta con la opinión de S. GAMBino (2010: 102), cuando afirma que el reconocimiento de los derechos fundamentales a través de la CDFUE «desvela una vocación nueva, capaz de asegurar mayor vitalidad y realce a conceptos igualmente esenciales en el proceso de construcción europea, como el concepto de ciudadanía de la Unión o el significado de la "confianza mutua entre los Estados"». 
1. $\quad$ Los Tratados, norma de cierre del sistema jurídico común, son fuente de la ordenación del poder público pro unione. La distribución y la articulación de ese poder se realiza con una visión utilitarista y funcionalista y, por ello, con el fin de lograr el efecto útil del Derecho Europeo, algo a lo que ha contribuido de forma determinante la jurisprudencia del Tribunal de Justicia. En buena medida, se podría decir que muchos avances en la defensa de los derechos de los ciudadanos han tenido como fin último la efectividad del Derecho Europeo, más que la protección de los ciudadanos. Esto es, en términos generales, correcto y la instrumentalización del procedimiento administrativo con la finalidad de alcanzar el effet utile es un buen ejemplo de ello ${ }^{49}$. Sin embargo, en el marco del principio de reconocimiento mutuo no se puede desconocer que se produce una coincidencia entre ambos fines: lograr el effet utile del Derecho Europeo es garantizar y proteger los derechos de los ciudadanos, pues la efectividad del Derecho Europeo pasa aquí por salvaguardar las libertades básicas comunitarias.

2. ${ }^{\circ} \quad$ Las Administraciones nacionales en el seno del mercado interior, cuando actúan en una orientación pro unione, y no meramente en el plano doméstico, actúan sujetas a la legalidad europea. La noción de un ordenamiento integrado permite identificar la noción de supralegalidad europea que integra e incorpora la pluralidad de los distintos ordenamientos jurídicos nacionales ${ }^{50}$. Conectado con el ejercicio de los derechos inherentes a la ciudadanía europea, se puede afirmar que la ciudadanía es un elemento de unidad (fundamenta pasarelas entre ordenamientos nacionales bajo el marco principial de los Tratados y en el ejercicio de los derechos de ciudadanía), pero también de diferencia, pues bajo esa supralegalidad se integran diversos ordenamientos nacionales cuya aplicación selectiva depende de la articulación del principio de reconocimiento mutuo en su vertiente conflictual.

3. ${ }^{\circ}$ La clave de la aplicación del principio de país de origen que caracteriza al reconocimiento mutuo depende de un presupuesto que conecta con la titularidad de derechos reconocidos al más alto nivel de jurisdicción territorial: sólo es imputable al titular del derecho la elección del Derecho aplicable (el del país de origen), es decir, en nuestro caso, al profesional que pretende ejercer su actividad en otro Estado miembro. La elección del Derecho aplicable constituye una decisión indivi-

49 Véanse J.-P. Schneider (2008: 44 y ss.) y D.-U. GALEtTa (2009).

50 Mediante su equivalencia interordinamental forjada por procesos de convergencia de intensidad variable que van desde la comunidad en valores compartidos, la convergencia vía jurisprudencia del Tribunal de Justicia o la armonización de legislaciones. Sobre estos aspectos, S. VALAGUZZA (2008). 
dualizadora de la norma aplicable. Esta idea de la elección del Derecho como un proceso de individualización conecta con un presupuesto anterior a la propia elección que es la existencia de una "competencia entre ordenamientos» entre los que cabe optar. Sobre ello volveremos más adelante, pero el efecto determinante que no se puede dejar de resaltar ahora es que dicha elección es un elemento instrumental para conseguir la efectividad, en el caso concreto, de la eficacia transterritorial de las libertades comunitarias.

4. $\quad$ Esta afirmación tiene consecuencias de calado en la dogmática jurídica: a) la evocación de una construcción de un Derecho Administrativo Europeo desde abajo, desde el ciudadano, se constata incluso en la propia determinación de la normativa que va a ser aplicada en el Estado de acogida; b) la segunda consecuencia tiene un plano de abstracción mayor, pues la trascendencia jurídica de la elección del Derecho aplicable matiza los términos aplicativos clásicos del principio de legalidad en su versión estatalista, habilitando la ruptura de la equiparación entre sometimiento al Derecho y jurisdicción territorial: se quiebra la exclusividad del Derecho estatal, consecuencia tradicional de la soberanía normativa estatal ${ }^{51}$.

La vinculación al Derecho Europeo en el seno del mercado interior (para la efectividad de las libertades comunitarias) conlleva la vinculación al Derecho positivo foráneo en una suerte de integración hacia arriba. Es mediante esa elección del Derecho aplicable que la idea de unidad versus diferencia que imputábamos a los derechos de libre circulación cobra pleno sentido: la elección del Derecho del país de origen conecta la aplicación del Derecho nacional con la supralegalidad europea. De la diversidad de ordenamientos nacionales se pasa a la aplicación de un Derecho nacional en virtud de la habilitación que el Derecho Europeo otorga al titular de las libertades europeas de elegir el Derecho aplicable. En síntesis, la reconducción a la unidad quedaría condicionada por dos datos: a) la existencia de "pasarelas» entre ordenamientos nacionales (origen-acogida) ${ }^{52}$ que se concretan en la aplicación e «interiorización» de un ordenamiento distinto al nacional (el Estado de acogida asume un título otorgado conforme a otro ordenamiento jurídico); b) la operatividad práctica de la pasarela interordinamental con base exclusiva en la elección del Derecho foráneo aplicable (y el reconocimiento de los actos dictados conforme a él), por quienes desean ejercer los derechos en que se concretan las libertades comunitarias.

51 En el mismo sentido, M. GNES (2004: 450, 454, 469 y 479).

52 Utiliza esa expresión S. CASSESE, citado por L. DE LUCIA (2009: 4). 
5. ${ }^{\circ} \quad$ La elección realizada por el ciudadano es la única actuación jurídica que puede construir el iter jurídico para el reconocimiento y efectividad de sus derechos. Esto significa que la decisión del interesado configura en cada caso y de forma dinámica la legalidad europea ${ }^{53}$. Esta afirmación tiene consecuencias jurídicas relevantes: a) la determinación de la norma aplicable y la vinculación al Derecho extranjero en virtud de la supralegalidad europea conlleva la inaplicación y no vinculación al Derecho interno, en una suerte de ineficacia parcial y puntual del principio de legalidad en sentido tradicional/estatalista ${ }^{54}$; b) esto no quiere decir que las normas no aplicadas no gocen de la misma fuerza vinculante que el resto del ordenamiento interno; lo que quiere decir es que esa fuerza jurídica depende de un acto de autonomía individual que impide que la norma aplicable genere plenamente tales efectos; y c) de esta afirmación previa se obtiene una conclusión adicional: la fuerza vinculante del Derecho no es constante, pudiéndose hablar de grados de imperatividad ${ }^{55}$.

3. La integración del Derecho Público con principios de Derecho Privado: la relevancia de la autonomía de la voluntad

A) Premisa. La competencia entre ordenamientos y la elección del Derecho aplicable y de la Administración de acogida

La relevancia otorgada a la elección del Derecho aplicable no se limita a la configuración dinámica de la legalidad comunitaria otorgando validez y prescriptividad pro unione al Derecho (y a las actuaciones administrativas) del país de origen. Esa elección también implica seleccionar el ordenamiento de acogida que modula la intervención más o menos intensa de la Administración del Estado de acogida. Dentro del margen de actuación que habilita la Directiva 2005/36, el profesional puede seleccionar, por ejemplo, aquel Estado cuyo Derecho sea menos estricto al regular la supervisión del reconocimiento de cualificaciones profesionales, pero también ha de elegir a la Administración que va a aplicar el Derecho del país de origen, lo que puede ser muy relevante en términos de eficiencia operativa.

53 En una dirección similar, M. GNEs (2004: 471), G. CoRso (2007: 130) y F. Viola (2007: 184).

54 Al respecto, F. Viola (2007: 184 y 193).

55 En este sentido, F. Viola (2007: 196), citando a A. ZopPINI. 
En este marco decisional, el profesional tiene un abanico de posibles decisiones que no es desdeñable. En primer lugar, debemos tener en cuenta que el Derecho de origen cuya aplicación elige el profesional no tiene por qué corresponder con el Derecho del Estado del que es nacional $^{56}$. En estas condiciones de inicio, el interesado ha de elegir el Derecho aplicable en un marco de «competencia entre ordenamientos» ${ }^{57}$. En segundo lugar, el interesado ha de elegir el Estado de acogida en el que desea ejercer su actividad; ese Estado incluso puede ser aquel del que es nacional si, como ya hemos indicado, el título que pretende reconocer lo obtuvo en otro Estado miembro. Este catálogo de elecciones deberá transformarse en decisiones concretas que dependerán de factores diversos, pero que, en todo caso, responden a criterios estrictamente «estratégicos» que permitan individualizar la norma más favorable para el profesional en términos de maximización de costes y beneficios $^{58}$.

56 Recordemos que en la STJUE de 27 de junio de 2013 (C-575/11, Nasiopoulos) un ciudadano griego pretende que se reconozcan en su propio país ciertas cualificaciones profesionales obtenidas en Alemania.

Por otro lado, aquí debemos apuntar que el planteamiento que ahora introducimos implica abrir el ámbito de reflexión más allá de la aplicación de la Directiva 2005/36. Aquí, lógicamente, entramos en el campo de la elección de la norma que regula en origen la obtención de títulos. Sobre la distinción y relación con el reconocimiento de cualificaciones profesionales, véase R. GonZález Miguel (2007).

57 La noción de competencia entre ordenamientos y la elección del Derecho han sido estudiadas principalmente desde la perspectiva del Derecho Internacional Privado a raíz de la STJCE de 9 de marzo de 1999 (C-212/97, Centros) en el marco del Derecho de Sociedades. El estado de la cuestión, en F. J. Garcimartín (2000). En Derecho Público, un trabajo imprescindible es el de M. GNES (2004). En España se han pronunciado sobre este tema M. BALLBÉ y C. PAdRós (1997: 135 y ss.), M. GARDEÑEs (1999: 229 y ss.) o L. ARRoyo (2004: 257 y ss.).

Los hechos que dieron lugar a la citada sentencia Centros son bien conocidos. Un matrimonio danés residente en Dinamarca decide realizar actividades empresariales en dicho país operando como una sociedad inglesa (una private limited company del Derecho inglés). La razón para ello fue evitar la aplicación de las normas sobre capital mínimo del Derecho danés, en la medida en que la legislación del Reino Unido era mucho más favorable en ese sentido. Por tanto, a pesar de que la dirección efectiva de la sociedad y sus actividades principales se localizaban en Dinamarca, prefirieron operar bajo una sociedad inglesa con domicilio social en Inglaterra. Los problemas surgieron al solicitar la inscripción de una sucursal en Dinamarca. La sucursal iba a ser, de hecho, el establecimiento principal de la sociedad. Las autoridades danesas denegaron la inscripción argumentando que la sociedad tenía su centro de actividades económicas en Dinamarca, que no realizaba ninguna actividad económica en el Reino Unido y que su única intención al constituirse como sociedad del Derecho inglés era eludir las normas danesas. La sentencia se pronuncia favorablemente sobre la «elección del Derecho", afirmando que "el hecho de que un nacional de un Estado miembro que quiere crear una sociedad elija constituirla en otro Estado miembro cuyas normas de Derecho de sociedades le parezcan las menos rigurosas y abra sucursales en otros Estados miembros no puede constituir por sí solo un uso abusivo del Derecho de establecimiento. En efecto, el derecho a constituir una sociedad de conformidad con la legislación de un Estado miembro y a crear sucursales en otros Estados miembros es inherente al ejercicio, dentro de un mercado único, de la libertad de establecimiento garantizada por el Tratado».

58 Los motivos que pueden llevar a un profesional a elegir el Derecho de origen aplicable en destino pueden ser motivos estrictamente económicos (pago de tasas, número de años de 
Este planteamiento permite corroborar que el principio de reconocimiento mutuo invierte y transforma la relación lineal y estática entre ordenamiento jurídico nacional/autoridades nacionales/administrado nacional que se deriva de una aplicación positiva del principio de legalidad. La conexión del principio con la vertiente sustantiva de las libertades comunitarias habilita al ciudadano para elegir el ordenamiento (del país de origen) que considere más adecuado a sus intereses (aquel más permisivo o más diligente en el plano administrativo, pero también con mayor reconocimiento en el campo profesional...), así como seleccionar a los poderes públicos encargados de reconocer ese derecho entre todas las autoridades nacionales de la Unión Europea, con base en motivos similares. La relación ahora es plural y abierta: ciudadano europeo/ordenamientos jurídicos nacionales/supralegalidad europea/autoridades nacionales.

Deben hacerse varias matizaciones. En este contexto se ha de advertir, en primer lugar, que el antagonismo que pudiera deducirse de la idea de elección del Derecho aplicable y de la idea de competencia entre ordenamientos se supera mediante la reducción a la unidad del ordenamiento europeo a la que ya nos hemos referido: la competencia entre ordenamientos nacionales no implica, por tanto, primacía de un ordenamiento sobre otro, sino la aplicación de un Derecho nacional (el de origen) orientado al ejercicio efectivo y no entorpecedor de las libertades comunitarias. Así pues, la competencia entre ordenamientos y la elección del Derecho aplicable es instrumental a la plena efectividad de las libertades europeas.

Otro aspecto a destacar es que la competencia de ordenamientos es un presupuesto para la elección del Derecho aplicable que no tiene siempre consecuencias positivas. Algo positivo es que la competencia de ordenamientos habilitada por el Derecho Europeo puede generar un proceso de armonización espontánea. Esto no es tan visible en las profesiones armonizadas, pero en las no armonizadas la atracción de ciudadanos que pretendan obtener una cualificación profesional determinada puede dar lugar a un proceso de aproximación de legislaciones hacia la del Estado miembro que tenga más éxito entre los profesionales. Sin embargo, la competencia entre ordenamientos genera también un riesgo evidente de direccionamiento de los Derechos nacionales en una

estudio...), pero también motivos de conveniencia como la dificultad de obtener un título (lo que podría llevar a elegir el país donde se estime más fácil lograrlo) o el prestigio (en cuyo caso podría elegirse un país más exigente). En la elección del país de acogida desde luego que también pueden incorporarse elementos de esa misma índole, pero parece determinante la elección de una Administración eficiente. Aquí podrá valorarse si se exige o no pasar una prueba de aptitud, pero también si el procedimiento suele ser rápido. 
tendencia homogeneizadora hacia abajo, es decir, hacia parámetros cada vez menos exigentes ${ }^{59}$, en el entendimiento de que cuanto menores sean las exigencias imponibles a los ciudadanos, mayores serán las posibilidades de que los ciudadanos elijan ese país para obtener su título. Este efecto es claramente negativo. Sin embargo, no lo es necesariamente si ese resultado se observa desde el país de acogida. En este caso, la posibilidad de race to the bottom también puede surgir, aunque con la limitada dimensión que la armonización por la Directiva 2005/36 permite. Dentro de las alternativas que establece la Directiva, la igualación por abajo se producirá en la medida en que los ordenamientos nacionales se equiparen al menos exigente al proceder al reconocimiento ${ }^{60}$. Esto puede ser negativo si sirve para atraer a malos profesionales, pero puede ser positivo si se admite que también podrá atraer a los buenos y, sobre todo, si se analiza desde el objetivo sustantivo que condiciona la optimización en cada caso del principio de reconocimiento mutuo: el ejercicio efectivo de la libre circulación.

En términos generales, no se puede decir que la elección del Derecho aplicable responda a criterios unidireccionales medidos en términos estrictamente cuantitativos (cuánto me ahorro, cuánto tiempo durará...; en definitiva, cuánto cuesta). Esta posición permite justificar que el legislador para comportarse racionalmente no debe moverse sólo por impulsos que midan la «comodidad» de los profesionales con su normativa. La racionalidad del legislador incluye también elementos de prestigio, reconocimiento y distinción. Y esto puede observarse tanto cuando un Estado actúa como Estado de origen (expedición de titulaciones profesionales) como cuanto actúa como Estado de acogida (reconocimiento de cualificaciones). De hecho, los profesionales pueden encontrar en los ordenamientos más exigentes beneficios que nada tienen ver con el ahorro de costes. En este sentido, los «mercados» nacionales que funcionen bien no parece que tengan ninguna necesidad

59 Véanse L. Arroyo (2004: 262 y ss.), A. NiCOLussi (2007: 29 y 44) o G. CoRso (2007: 127). Sin embargo, los argumentos utilizados permiten deducir que ese efecto no es automático, sino variable.

60 En cualquier caso, este efecto no parece tan real a la vista de la jurisprudencia del TJUE. No en vano, los Estados miembros se han mostrado reticentes a la incorporación de la Directiva tanto para salvaguardar niveles de cualificación adecuados, como para limitar el acceso. Así lo demostrarían los incumplimientos declarados por las SSTJUE de 2 de julio de 2009 (C-567/08, Comisión v. Luxemburgo), 9 de julio de 2009 (C-556/08, Comisión v. Reino Unido), 17 de diciembre de 2009 (C-505/08, Comisión v. Alemania), 24 de septiembre de 2009 (C-477/08, Comisión v. Austria), 9 de julio de 2009 (C-469/08, Comisión v. Bélgica), 1 de octubre de 2009 (C-468/08, Comisión v. Francia) y 2 de julio de 2009 (C-465/08, Comisión v. Grecia). España tradicionalmente no ha sido un ejemplo de lo contrario, como demuestran los incumplimientos de la Directiva 89/48: SSTJUE de 26 de enero de 2006 (C-514/03), 8 de mayo de 2008 (C-39/07), 16 de octubre de 2008 (C-136/07) o 23 de octubre de 2008 (C-286/06). 
de un race to the bottom. Al contrario, otros Estados que quieran pretender ese éxito, necesariamente deberán tratar de igualar por arriba su legislación. Ningún Estado racional estará tentado de modificar ni su sistema de obtención de títulos, ni su régimen de reconocimiento, si eso implica bajar la calidad de los futuros profesionales y dejar entrar en su mercado a personas sin la cualificación adecuada ${ }^{61}$.

\section{B) La relevancia de la autonomía de la voluntad en el Derecho Administrativo}

La capacidad electiva del Derecho aplicable imputable al profesional opera con base en parámetros de maximización de beneficios que son más propios de las relaciones inter privatos. El principio de reconocimiento mutuo habilita la elección del Derecho aplicable y de la Administración competente para reconocer el ejercicio de las libertades comunitarias, intentando maximizar las expectativas del profesional $^{62}$. Esto implica que la autonomía de la voluntad es el elemento determinante para la aplicación del Derecho Administrativo: el Derecho Administrativo como Derecho cuya aplicación y prescriptividad actual no dependen del poder público investido de competencias por el ordenamiento jurídico nacional, sino de la decisión del ciudadano investido de derechos por el Derecho Europeo ${ }^{63}$. La conclusión que se detrae de todo ello es muy relevante: la subjetivización del Derecho objetivo, en la medida en que la fuerza del Derecho depende de los intereses del sujeto privado interesado ${ }^{64}$.

A pesar de esta afirmación, se ha de tener en cuenta que la elección del Derecho aplicable tiene consecuencias distintas en la esfera del Derecho Privado y en el ámbito del Derecho Público. En las relaciones jurídico-privadas, la elección puede tener consecuencias negativas pues, a pesar de estar gobernadas por el principio de igualdad, la capacidad

61 M. GNES (2014: 17) apunta esa dualidad de efectos: race to the top versus race to the bottom.

62 Para M. Gnes (2014: 17 y 18), la competencia o concurrencia de ordenamientos, presupuesto de la scelta del Diritto, tienen como efecto la mercatizzazione del Derecho. El efecto inmediato es la cosificación del Derecho y su consideración como un producto (law as a product) (pág. 269).

63 Este efecto muestra, como señala F. Viola (2007: 194), «la tendenza del diritto nel suo complesso, privato e pubblico, ad aprirsi sempre più al valore dell'autonomia». Igualmente, M. GNES (2004: 459). Este efecto encaja con la propuesta explicativa y superadora de la summa divisio entre Derecho Público y Derecho Privado que propone F. Velasco (2014), y que explica la existencia de grados de ius privaticidad en el Derecho Público (y viceversa).

64 Véanse A. Nicolussi (2007) y F. Viola (2007: 197 y 198). 
de elección suele ser favorable a la parte más fuerte de la relación jurídica, que puede pretender imponer a la más débil el Derecho aplicable porque le sea más ventajoso. Sin embargo, lo trascendente en el ámbito del Derecho Público es que se puede producir un efecto inverso y otro adicional: $\left.1 .^{\circ}\right)$ Inverso, porque como sucede en la libre circulación de profesionales, es la parte más débil la que elige el Derecho que ha de ser aplicado, así como la Administración actuante. Esto es un efecto coherente con el sentido de la libre circulación, pues favorece la posición jurídica del titular del derecho, sin perjuicio de que ese mismo efecto pueda constituir un mecanismo de debilitamiento de la posición de los poderes públicos (entendidos en un contexto pro unione) frente a los particulares; por ejemplo, en el caso de que el Estado de acogida sea especialmente poco exigente en el control de las cualificaciones profesionales de origen. $2^{\circ}{ }^{\circ}$ ) Adicional, porque la elección del Derecho aplicable realizada en el marco del Derecho Público condiciona las relaciones jurídico-privadas entre el profesional y terceras personas. Desde este punto de vista, la relación del profesional con sus clientes o pacientes queda sometida en parte al Derecho foráneo. Aquí la clave es la protección de los derechos de los usuarios, consumidores y pacientes y su adecuada información ${ }^{65}$.

\section{C) Afección a la legitimidad de la actuación administrativa}

La elección del Derecho tiene también repercusiones en la legitimidad de la actuación administrativa. Parece evidente el efecto negativo que tiene en la legitimidad democrática de la actuación administrativa la desvinculación de la aplicación inmediata de la ley. Esto no quiere decir que la legitimidad imputable al principio de legalidad haya sido la única fuente de legitimidad administrativa ${ }^{66}$. Muy al contrario, la idea de complementariedad de las fuentes de legitimación y la consiguiente vigencia de una escala de optimización gradual de la legiti-

65 Recuérdese, por ejemplo, en el marco de la prestación de servicios, que el artículo 5.3 de la Directiva 2005/36 establece que los profesionales que se desplacen a otro Estado miembro se someterán a la normativa del Estado de acogida en materia de responsabilidad profesional y disciplinaria, o bien el artículo 9, según el cual cuando la prestación se realice al amparo del título del Estado de origen, el Estado de acogida puede solicitar al profesional que facilite al destinatario del servicio información adicional sobre sus cualificaciones y sobre las particularidades que rigen la prestación

66 Una completa explicación acerca de las diferentes fuentes de legitimación administrativa a lo largo de los distintos paradigmas definidores de la actuación de la Administración, en J. Ponce (2010: 90 y ss.). 
mación de la actuación de la Administración ${ }^{67}$ ha sido y es una evidencia que se enfatiza con el principio de reconocimiento mutuo y la salvaguardia de las libertades comunitarias.

La optimización del principio de reconocimiento mutuo mediante la elección del Derecho aplicable irradia sobre la Administración de reconocimiento la legitimidad que otorga la titularidad y el ejercicio efectivo de los derechos de libre circulación reconocidos en los Tratados. Además, la propia decisión personal del interesado compensa en términos legitimatorios las limitaciones imputables desde esta perspectiva al principio de legalidad. Por un lado, porque se trata de una decisión personal y, en principio, voluntaria, y, por otro lado, porque esa decisión también goza de una carga democrática en términos de legitimación ${ }^{68}$. Finalmente, y conectando con la vertiente formal del principio de reconocimiento mutuo, cabe también advertir que esa actuación administrativa está orientada estrictamente a la satisfacción de las libertades comunitarias, de modo que, desde este punto de vista, la actuación administrativa se legitima en virtud de su eficacia medida en términos de resultados. Esto, en última instancia, nos reconduce a la legitimidad que imprime la titularidad y el ejercicio efectivo de los derechos reconocidos por los Tratados.

\section{REFLEXIONES FINALES. DiSCRIMINACIÓN INVERSA Y EXTENSIÓN DEL RECONOCIMIENTO MUtUO: LA LEY DE UNIDAD DE MERCAdo}

A cualquier intérprete objetivo no se le escapará un detalle que por el mero hecho de ser evidente no deja de ser menos trascendente. Es incontestable que el reconocimiento mutuo plantea problemas de discriminación inversa ${ }^{69}$, pues no se pueden desconocer los efectos perniciosos que se pueden generar comparando la situación jurídica de los ciudadanos integrados en relaciones jurídicas sometidas al Derecho Europeo con otras sujetas al Derecho interno que presentan una equidistancia similar temática y administrativamente hablando.

67 Al respecto, E. Schmidt-Assmann (2011b: 53 y ss.) o F. Velasco (2011: 92 y ss.).

68 Para F. Viola (2007: 198), «il materializzarsi del diritto nel tempo e nello spazio depende anche dall'uso che di ello fan no gliutenti delle norme. Il diritto si rende ancora più sensibile alla democracia». Incluso cabe atribuir efectos legitimatorios democráticos a la competencia entre ordenamientos en los términos expuestos por M. BALlBÉ y C. PADRós (1997: 154), en la medida en que "la competencia entre legislaciones supone hacer surgir los poderes representativos de los Estados y de sus legislaciones que no adolecen de un déficit democrático», como sí sucede con las instituciones comunitarias.

69 Al respecto, M. GNEs (2004: 301 y ss.). 
La evitación de la discriminación en las situaciones jurídicas domésticas puede lograrse por vías diversas, pero una, probablemente la más efectiva, es la aplicación voluntaria, a través del conocido como efecto spill-over ${ }^{70}$, de mecanismos y consecuencias jurídicas similares a las aplicables a situaciones sometidas al Derecho Europeo. Este efecto permite salvaguardar la coherencia interna de los ordenamientos jurídicos, evitando diferencias estructurales derivadas de la aplicación diversa del Derecho Europeo y del Derecho nacional a relaciones jurídicas similares ${ }^{71}$. Dicho de otro modo, la eventual discriminación que pudiera derivarse de la aplicación de criterios jurídicos distintos en situaciones jurídicas semejantes insta a los poderes públicos a la incorporación de criterios jurídicos homogéneos para todas las relaciones jurídicas ${ }^{72}$.

Un magnífico ejemplo en el marco de nuestro análisis es el artículo 5.5 de la Ley 25/2009, de 22 de diciembre, la «Ley ómnibus» de la Ley de Servicios, que modifica el artículo 3 de la Ley 2/1974, de 13 de febrero, sobre Colegios Profesionales, estableciendo el reconocimiento a nivel nacional de la colegiación en una Comunidad Autónoma. Los términos en los que se prevé la exención de colegiación, una vez que el profesional se encuentra preceptivamente colegiado en cualquiera de los Colegios Profesionales del ramo en España, permiten que el ejercicio de la actividad profesional sea parecido al que desarrollaría un profesional nacional de otro Estado miembro que, recordemos, en el marco de la prestación de servicios, queda dispensado de la carga de colegiación.

Fuera de esta materia, un salto cualitativo en la extensión aplicativa del reconocimiento mutuo se encuentra en la Ley 20/2013, de 9 de diciembre, de garantía de la unidad de mercado (LGUM). Este paso consiste en la plena interiorización y generalización del principio de reconocimiento mutuo ${ }^{73}$ :

70 Véanse R. CARAnta (1997: 234), J. Schwarze (2006: clxxxviii) o J. H. Jans et al. (2007: 8).

71 En relación con esta cuestión, E. SchmidT-Assmann (2003: 401 y 402) aplica la que denomina «tesis del paralelismo» para evitar diferencias valorativas entre los Derechos nacionales y el Derecho Europeo: es necesario mantener un estándar común de protección en todos los procedimientos administrativos con independencia del Derecho aplicable.

72 Como afirma F. Viola (2007: 173), esto es consecuencia de que «l'economia non tollera la distinzione tra cittadini e stranieri».

73 Su Exposición de Motivos afirma que «con esta Ley se dota de eficacia en todo el territorio nacional a las decisiones tomadas por la autoridad competente de origen basadas en un criterio de confianza mutua, y se aplican principios comunes como el principio de eficacia en todo el territorio nacional de las actuaciones administrativas en la libre iniciativa económica, lo que implica el reconocimiento implícito de actuaciones de las autoridades competentes de otras Administraciones públicas». Para lograr ese efecto, la Ley no toma como base 
1. La incorporación del principio de reconocimiento mutuo está dirigida a la optimización de principios y valores sustantivos constitucionales como la unidad de mercado ${ }^{74}$, la libertad de circulación y la igualdad de derechos en todo el territorio nacional, la libertad de empresa y la no discriminación (inversa). Esta vertiente axiológico-sustantiva se complementa con otra de tipo formal: la consideración del reconocimiento mutuo como una manifestación específica del principio de cooperación y, por extensión, del principio de lealtad institucional (art. 4 de la LRJPAC) ${ }^{75}$, en conexión con el principio de eficacia administrativa (art. 103 de la Constitución).

2. Calificar al reconocimiento mutuo como un mecanismo cooperativo implica que debe articularse necesariamente en términos de igualdad e imposibilidad de imposición unilateral de una decisión jurídica determinada. No cabe duda de que el reconocimiento mutuo satisface estos presupuestos. Ahora bien, el problema no es tanto éste como si la articulación del reconocimiento mutuo puede ser impuesta por el legislador estatal. Sobre la imposición de mecanismos cooperativos en ejercicio de competencias exclusivas y básicas del Estado ya se ha pronunciado favorablemente la mejor doctrina ${ }^{76}$, aunque es cierto que en ningún caso se hacía alusión al principio de reconocimiento mutuo. Admitiendo el difícil deslinde entre técnicas cooperativas y de

jurídica ninguna norma europea, sino que «al tratarse de una Ley fundamentada exclusivamente en el Derecho interno, la fundamentación de cuanto propone debe moverse claramente dentro de los límites de la Constitución» (voto particular de E. Alonso GaRcía al Dictamen del Consejo de Estado núm. 631/2013, emitido en relación con el anteproyecto de LGUM).

74 Ya la STC 1/1982 exigió la aplicación con carácter unitario y general de los principios básicos del orden económico, lo que no es incompatible con el respeto de las competencias autonómicas y, por ello, con la diversidad normativa (SSTC 37/1981, 88/1986, 64/1990, etc.). Tras la aprobación de la LGUM se ha discutido si el sistema de distribución competencial español ha tenido como efecto la ruptura de la unidad de mercado. Las opiniones son variadas, pero hasta los detractores de la Ley admiten que el mercado español se caracteriza por un exceso regulador y por una lentitud administrativa que, se afirma, no tiene por qué suponer la ruptura de la unidad de mercado, aunque también se advierte de que puede romper el mercado en sí mismo con burocracia y barreras de entrada. Desde luego, es matizable si crear barreras es lo mismo que romper la unidad de mercado, pero en ese contexto la LGUM intenta imponer cierta racionalidad. Por eso es razonable que el Consejo de Estado afirmara en el Dictamen 631/2013 que «valora positivamente la regulación contenida en el anteproyecto, que, en un marco regulatorio de enorme complejidad como el actual, puede servir para restablecer eficazmente el equilibrio entre la diversidad de normas territoriales y la unidad de mercado, cuya garantía se encomienda al Estado».

75 Para L. Parejo (2007: 164), el principio de colaboración se vincula a la solidaridad del artículo 2 de la Constitución en clave de lealtad institucional (STC 64/1990). Más adelante (pág. 172) añade que la colaboración, en sentido amplio, cumple el mismo papel que en la Unión Europea el principio de lealtad.

76 Véanse A. Menéndez ReXach (1994: 44-47), L. Morel Ocaña (1994: 54 y ss.) y L. Parejo (2007: 184 y ss.). 
coordinación, en última instancia podría aceptarse que la imposición del reconocimiento mutuo es el resultado del ejercicio de funciones estatales de coordinación mediante la imposición de mecanismos cooperativos ${ }^{77}$.

Aquí, el Estado ni impone una decisión unilateral en el ámbito de las competencias ajenas ni tampoco, por el hecho de establecer mecanismos de reconocimiento mutuo, vacía de contenido las competencias autonómicas ${ }^{78}$. La crítica se encuentra en lo que más tarde se dirá respecto de los artículos 5, 17 y ss. de la LGUM. Pues bien, atendiendo sólo al mecanismo de reconocimiento mutuo, se puede afirmar que lo que se persigue, en la línea de las SSTC 32/1983, 144/1985 y 102/1995, entre otras, es «la integración de la diversidad de las partes o subsistemas en el conjunto o sistema, evitando contradicciones o reduciendo disfunciones que, de subsistir, impedirían o dificultarían, respectivamente, la realidad misma del sistema». Esta función instrumental consistiría en fijar «medios y sistemas de relación que hagan posible la información recíproca, la homogeneidad técnica en muchos aspectos y la acción conjunta de las autoridades... estatales y comunitarias en el ejercicio de sus respectivas competencias, de tal modo que se logre la integración de actos parciales». En nuestro caso, el objetivo de un conjunto operativo unitario se lograría con la imposición general del reconocimiento mutuo, cuya aplicación por las Administraciones competentes es esencialmente cooperativa. El matiz fundamental es que esta unidad funcional no se establece para que el Estado asuma competencias ajenas, sino para regular un mecanismo común que determina soluciones operativas unitarias (coordinar para cooperar). Este matiz sirve para afirmar que no es acertado hablar de una supuesta recentralización de competencias ${ }^{79}$, ya que el Estado no asume competencia ajena alguna, sino que establece soluciones cooperativas unitarias sobre ámbitos que siguen siendo de competencia autonómica.

3. Una duda que plantea la afirmación anterior es si la imposición del reconocimiento mutuo podría ser considerada una vulneración del

77 Esa posibilidad es puesta de manifiesto por L. PAREJo (2007: 188).

78 La STC 27/1987 señala que la coordinación es la facultad de intervenir en el ámbito de las competencias ajenas, pero sin vaciarlas de contenido.

79 En este sentido, es interesante observar las contradicciones doctrinales a la hora de calificar, en el contexto europeo, el protagonismo de las instituciones comunitarias o de los Estados miembros en la ejecución del Derecho Europeo en el marco de la aplicación del principio de reconocimiento mutuo. Por ejemplo, J.-P. SchneIDER (2008: 28) habla de que el principio transnacional que gobierna el mercado interior tiene como efecto una «centralización horizontal de las competencias». Sin embargo, M. RUFFERT (2008: 98) se refiere a esa realidad calificándola de ejecución descentralizada. 
principio de irrenunciabilidad de las competencias. Sin embargo, no se puede afirmar que las CC.AA. renuncien a sus competencias en el marco (coordinado) de cooperación horizontal propio de las relaciones de reconocimiento mutuo. Todas ellas podrán seguir dictando actos en las materias de su competencia y, cuando actúen como Administración de acogida, su competencia se encuadrará en funciones propias de verificación y de supervisión ${ }^{80}$. La admisión de la supraterritorialidad de los actos administrativos foráneos y, en consecuencia, del no ejercicio pleno de las competencias propias se expresaría en la reciprocidad que caracteriza al reconocimiento mutuo y, tácitamente, con la verificación y supervisión de la actuación ajena y, en su caso, con la no aplicación subsiguiente de las excepciones al reconocimiento mutuo. Aquí, no obstante, luego se insistirá sobre las insuficiencias de la LGUM.

Otra duda es si la eventual irrenunciabilidad de las competencias propias exigiría que fueran las propias CC.AA. quienes, voluntariamente y en el marco de relaciones bi/multilaterales, alcanzasen soluciones similares (convenios entre CC.AA.). Por utilizar un parangón útil, es bien conocida la jurisprudencia constitucional que ha enfatizado que la solución a los problemas de la supraterritorialidad de la acción administrativa debe ser alcanzada mediante la articulación de mecanismos colaborativos entre las CC.AA. ${ }^{81}$. Sin duda, ésta podría ser una solución. Sin embargo, esa solución, en los mismos términos que hemos señalado páginas atrás en relación con el reconocimiento mutuo en el contexto europeo, no tendría por qué dar lugar a soluciones unitarias y comunes en toda España, acentuando así las diferencias aplicativas y las barreras burocráticas. Es cierto que la LGUM tal cual ha sido dictada tampoco garantiza aquel resultado, sobre todo por la crítica que merecen los artículos 5, 17 y 18 de la Ley y por la litigiosidad que, sin duda, van a generar. Ahora bien, esto no es un impedimento para que, como vamos a mostrar, el legislador estatal explore nuevos mecanismos de actuación cooperativa transterritorial.

4. La crítica a la LGUM nos lleva a una paradoja: admitimos con normalidad que un acto dictado en Lituania (o en cualquier otro Estado miembro) pueda tener efectos en España y que eso no suponga una re-

80 Dicho esto, se ha de estar de acuerdo con quienes, como S. MuÑoz MaCHADo (2014), critican que el legislador imponga un modelo de actuación en el que la intervención ex post gana en relevancia y, sin embargo, no se dedique un solo artículo a regular esa cuestión. Más tarde insistiremos sobre esta crítica.

81 Debemos recordar que ya la STC 102/1995 (FJ 19) afirmó con rotundidad que «la supraterritorialidad no configura título competencial alguno» que confiera competencias adicionales al Estado. 
nuncia de las competencias del Estado (o de las CC.AA. cuando afecte a sus competencias) bajo la premisa de que todo ello se fundamenta en la primacía del Derecho Europeo y, sin embargo, discutimos si un efecto similar puede ser admitido cuando un mecanismo idéntico tiene lugar en las relaciones entre CC.AA., pero en virtud de la legislación estatal. No es aceptable que esta conclusión sea mantenida sobre la existencia de una base jurídica fundada en una norma comunitaria, como si en ausencia de ese soporte jurídico el Estado no pudiera actuar en la misma dirección. Es de sobra conocida la jurisprudencia del Tribunal Constitucional que establece que la incorporación de España en las CC.EE. no alteró el régimen constitucional y estatutario de distribución de competencias ${ }^{82}$. Recordemos, en esta dirección, que la Ley 17/2009, de 23 de noviembre, de libre acceso a las actividades de servicio y su ejercicio, fue dictada con base en los títulos competenciales del Estado previstos en los apartados $1 .^{\circ}, 13 .^{\circ}$ y $18 .^{\circ}$ del artículo 149 de la Constitución, que son los mismos que sirven para fundar la aprobación de la LGUM. Esto quiere decir que si el Estado era competente para regular el reconocimiento mutuo en materia de servicios y otorgar eficacia supraterritorial a ciertos actos administrativos ${ }^{83}$ es porque ya ostentaba competencias que le legitimaban para ordenar (y coordinar cooperativamente) la actuación administrativa en ese sentido ${ }^{84}$ : el Derecho Europeo no le ha atribuido ninguna competencia que no ostentase con anterioridad. Por tanto, salvo que admitamos que la Ley de Servicios es inconstitucional porque el Estado carece de competencias para regular la aplicación en España del reconocimiento mutuo, la única conclusión a la que se puede llegar en relación con la LGUM es que los títulos competenciales reconocidos en los artículos 149.1.1. ${ }^{\mathrm{a}}, 13 .^{\mathrm{a}}$ y $18 .^{\mathrm{a}}$

82 Así lo viene manteniendo el Tribunal desde la STC 252/1988. Por consiguiente, la ejecución del Derecho comunitario corresponde a quien ya ostentaba la competencia sobre la materia en la que incida la norma europea (SSTC 64/1991, 76/1991, 236/1991, 79/1992, $141 / 1993,102 / 1995 \ldots)$.

${ }^{83}$ No comparto la opinión de quienes parecen considerar que la Directiva de Servicios regula algo distinto al reconocimiento mutuo. Como hemos puesto de relieve páginas atrás, hay tipos de reconocimiento mutuo gobernados por los mismos principios (equivalencia, confianza mutua, país de origen, cooperación); el matiz (importante) es la relevancia que asumen principios como el de país de origen en virtud del grado de automatismo del reconocimiento (reconocimiento automático versus condicionado).

84 S. MuÑoz MACHADO (2014) se pronuncia en contra de que el artículo 149.1.13 habilite al Estado a ese resultado en relación con la LGUM. J. ToRNos (2014: 163 y ss.) introduce varios criterios para apoyar esa afirmación en relación con el principio de eficacia supraterritorial, porque «no supone que el Estado defina un modelo básico y común de ordenación de la economía, ya que en el capítulo de la Ley relativo a dicho principio no se establece ninguna regla material de actuación». Sin embargo, en mi opinión, la LGUM tiene como finalidad implantar (con errores, como luego veremos) el modelo cooperativo de actuación administrativa que es inherente al reconocimiento mutuo. 
de la Constitución habilitan la coordinación de las Administraciones territoriales mediante mecanismos cooperativos similares.

A favor de esta conclusión cabe citar las SSTC 26/2012 y 193/2013, cuando afirman que «ninguna duda cabe de que las normas que se han expuesto tienen carácter básico desde un punto de vista formal pues ya hemos indicado que como tales se proclaman en la Ley de ordenación del comercio minorista y en la Ley 17/2009 mientras que, desde la perspectiva material, pueden ser consideradas previsiones básicas en materia económica en cuanto que prevén un marco más flexible y transparente para el acceso y ejercicio de las actividades de servicios, estableciendo que deben de eliminarse todos aquellos regímenes de autorización que no estén justificados por una razón imperiosa de interés general a fin de asegurar que los controles administrativos previos para el ejercicio de una actividad, en este caso la comercial, no constituyan obstáculos indebidos para el acceso al mercado. El Estado puede legítimamente perseguir estos objetivos al amparo de sus competencias, en particular la relativa a la ordenación general de la economía ex art. 149.1.13 CE». Dejando a un lado la crítica que, sin duda, merece la LGUM, la pregunta es: ¿no es éste, o bastante parecido, el objetivo que pretende la LGUM?

5. Debemos recordar, por otra parte, que la supraterritorialidad de los efectos de los actos administrativos de las CC.AA. ha sido admitida por el Tribunal Constitucional, sin perjuicio de tener que aceptar que lo ha sido en términos excepcionales ${ }^{85}$. Esa excepcionalidad puede ser entendida de dos modos: podemos considerar, por un lado, que las situaciones en que ese efecto puede producirse son excepcionales (pocos supuestos) ${ }^{86}$, o bien podemos entender que esas situaciones son más o menos habituales, pero que la atribución de esos efectos jurídicos es excepcional, dependiendo de que el legislador competente establezca las bases para que así sea y de que con ello no se enerven competencias ajenas ${ }^{87}$.

85 Las SSTC 13/1988, 48/1988, 44/1988, 49/1988 y 40/1998 han reiterado que el principio de territorialidad de las competencias es algo implícito al propio sistema de autonomías territoriales.

86 Desde un punto de vista meramente cuantitativo, el reconocimiento de actuaciones de la Administración de una Comunidad Autónoma con efectos en otra (más allá de las soluciones convencionales), o incluso fuera de España, no es tan infrecuente (p. ej., subvenciones lingüísticas, selecciones deportivas autonómicas, oficinas autonómicas comerciales...).

87 La STC 110/2012 (FJ 5), al abordar el principio de territorialidad, afirma que, en relación con las competencias de las CC.AA., «no excluye su excepcional estrategia extraterritorial ni su proyección, incluso más allá del territorio español, siempre y cuando no afecte a materias propias del ordenamiento internacional, ni se enerve o condicione el ejercicio de otras competencias que correspondan al Estado». 
La excepcionalidad puede ser entendida en el segundo sentido: a) Como premisa se ha de partir del entendimiento de que la supraterritorialidad ha sido considerada excepcional debido al mantenimiento de la lógica tradicional que vincula la eficacia de las actuaciones administrativas con el ámbito territorial correspondiente. b) Ahora bien, si el legislador competente (el estatal) establece los mecanismos para otorgar una eficacia supraterritorial a los actos administrativos de las CC.AA., la lógica del sistema no se resiente por varios motivos: primero, porque ese efecto no depende de una decisión unilateral del Estado ni de otra Comunidad Autónoma, sino de la decisión de los ciudadanos investidos de derechos al elegir el ordenamiento y la Administración de acogida (no hay, por tanto, extralimitación competencial); segundo, porque con ello se contribuye a equiparar la eficacia de esos actos con la de otros de las mismas Administraciones dictados, por ejemplo, con base en la Directiva de Servicios (de modo que se contribuiría a dotar de coherencia general al sistema); y tercero, porque, como luego se dirá en relación con las facultades que las CC.AA. deben mantener para otorgar o no ese efecto mediante el condicionamiento del reconocimiento mutuo, en un contexto estrictamente constitucional, la supraterritorialidad sólo puede ser considerada ajustada a la Constitución si las CC.AA. gozan de facultades suficientes y adecuadas para impedir o habilitar los efectos en su territorio de normas y actuaciones jurídicas ajenas. Aquí está la clave. Sobre ellos volveremos posteriormente.

6. Se podría decir que la LGUM es «una nueva forma de erosión autonómica porque si bien sus efectos no alcanzan a constituir una uniformización stricto sensu de la diversidad normativa interna, sí que desvalorizan la autonomía reguladora de las CC.AA. - puesto que la normativa autonómica más laxa acabará imponiéndose en todo el territorio nacional- (...). Así las cosas, a los ordenamientos jurídicos autonómicos no les va a quedar otra salida que entrar en una feroz competencia con el fin de ofrecer una producción jurídica más atractiva - y no necesariamente de mayor calidad regulatoria- a los ojos de los operadores económicos, que los convenza de los beneficios de establecerse en su territorio» ${ }^{88}$. La crítica parece fundarse en la competencia entre ordenamientos y la armonización tácita.

Debemos recordar que estos efectos son comunes y generalizados en la Unión Europea debido a la aplicación del principio de reconoci-

88 Cito a J. GRIFEU (2014: 205). En esta dirección, también J. ToRnos (2014: 156 y ss.) y C. PAdrós y J. M. Macías (2014: 128-129). 
miento mutuo; aparte, se pueden hacer las siguientes consideraciones: a) los efectos criticados no son exclusivos de la Unión Europea, pues efectos idénticos se producen con normalidad en Estados federales como Estados Unidos ${ }^{89}$; b) en cuanto a la competencia entre ordenamientos, no se puede desconocer que es ya una realidad en nuestro país y que, sin embargo, no ha despertado demasiada animadversión ${ }^{90}$; c) que el efecto race to the bottom (armonización tácita a la baja) no parece haber sido una consecuencia tan preocupante en la Unión Europea, al menos, como hemos expuesto, en materia de reconocimiento de títulos; y d) que la competencia entre ordenamientos, aparte de consustancial al reconocimiento mutuo, no es automática y, además, depende exclusivamente de que las propias CC.AA. decidan rebajar sus estándares de exigencia en sus respectivos ordenamientos ${ }^{91}$.

7. En este orden de consideraciones, buena parte de la doctrina ha manejado la noción de «dumping regulatorio» para describir el efecto derivado de la LGUM: «El principio de eficacia (supraterritorial) va más allá, ya que lo que pretende es conseguir que en todo el territorio nacional se imponga por la fuerza de los hechos aquella normativa más liberalizadora, aquella que contenga menos requisitos para el ejercicio de una actividad económica o para la circulación de un producto. Al imponer la extensión de esa normativa en los territorios de destino se está generalizando la aplicación de la normativa menos interventora. Esto es lo que se ha calificado como "dumping regulatorio” (...). El operador económico escoge el ordenamiento que le es más favorable y en virtud del principio de eficacia se dedica a desplazar las normativas o las intervenciones administrativas existentes en los lugares de destino ${ }^{92}$. Este efecto ya ha quedado explicado páginas atrás: el reconocimiento mutuo tiene como premisa la competencia de ordenamientos y el otorgamiento de relevancia jurídica a la elección del Derecho aplicable que desplaza la aplicación del Derecho propio. Este

89 La competencia entre ordenamientos se analiza a partir del conocido como «efecto Delaware» en Estados Unidos. Véase M. GNES (2004: 33 y ss.).

90 Ya ha sido planteada en esos estrictos términos por C. VARGAS (2004), quien explica la realidad del «efecto Delaware» en el Derecho cooperativo español. Pero no es el único ejemplo, pues la competencia entre ordenamientos autonómicos ha sido una realidad en la ordenación del equipamiento comercial y de horarios comerciales, en materia ambiental, en materia tributaria, etc.

91 J. ToRnos (2014: 169 y ss.) propone como alternativa el recurso a las Leyes de armonización; sin embargo, parece que esta opción sería más incisiva en las competencias de las CC.AA. Tal vez, por ello, el artículo 150.3 de la Constitución no haya tenido ningún recorrido en la práctica.

92 Cito a J. Tornos (2014: 160). 
efecto es la consecuencia de entender que el reconocimiento mutuo supone siempre aplicar las normas del "país (Comunidad Autónoma, en nuestro caso) de origen».

La pregunta es si ese efecto es admisible en nuestro sistema constitucional. Las citadas SSTC 26/2012 y 193/2013 se han pronunciado ya en relación con la Ley 17/2009 y lo llamativo es que ese efecto ni siquiera ha levantado ninguna sospecha. Es cierto, podría decirse, que esta apreciación se hace en un contexto de ejecución de normas europeas. Sin embargo, ese mismo efecto se asume en la Ley 25/2009, la «Ley ómnibus» de la Ley 17/2009, en algunos supuestos que ya hemos indicado (art. 5.5 en materia de colegiación), y aquí tampoco se ha hecho reparo alguno de inconstitucionalidad respecto del precepto cuando dispone lo siguiente: «... cuando en una profesión sólo existan colegios profesionales en algunas Comunidades Autónomas, los profesionales se regirán por la legislación del lugar donde tengan establecido su domicilio profesional único o principal, lo que bastará para ejercer en todo el territorio español». La STC 89/2013 ha confirmado la constitucionalidad de aquel precepto y la competencia estatal in genere para ordenar la colegiación obligatoria ${ }^{93}$, incluido indirectamente ese efecto de «dumping regulativo».

Debemos recordar, además, que la premisa aplicativa del reconocimiento mutuo es la equivalencia entre ordenamientos y la confianza mutua. Que ambos principios son inherentes a nuestro ordenamiento parece claro tratándose de un Estado unitario descentralizado, así como considerando los efectos armonizadores de la legislación estatal. No admitir esta premisa supondría dar la razón a quienes afirman que existe una ruptura de la unidad de mercado, pues mientras sería posible afirmar una equivalencia entre el ordenamiento español con el de cualquier otro Estado miembro de la Unión Europea, llegaríamos a la paradoja de admitir que esa misma equivalencia no existe entre CC.AA. ${ }^{94}$. Por tanto, es razonable admitir que nuestro sistema constitucional asienta las relaciones interordinamentales en principios se-

93 Confirmada en las SSTC 3, 46, 50, 63, 144 y 201, todas de 2013, y 84 y 150 de 2014

94 Se ha planteado la eventual discriminación que la LGUM puede generar según el origen del operador económico: quien haya optado por una Comunidad más intervencionista como Comunidad de origen podrá verse obligado a competir con otros operadores provenientes de Comunidades más liberalizadas. Esta afirmación es una clara expresión de que la fragmentación de la unidad de mercado sí puede tener algún riesgo. Pero aún más, dejando a un lado la LGUM, ¿acaso no se producen efectos similares siempre que un operador económico actúa en una Comunidad Autónoma proteccionista en comparación con otras menos intervencionistas? Lo paradójico es que lo que se propone es mantener las barreras de entrada en cada mercado autonómico para que todos los operadores «jueguen» con las mismas reglas; esto significa, lógicamente, que todos tendrían que pasar por el control administrativo correspondiente, duplicar controles y pasar por las mismas cargas burocráticas, reiterar costes administrativos... 
mejantes a los que propician el reconocimiento mutuo. Por este motivo, y partiendo de esta premisa, el supuesto dumping no es más que el efecto de la aplicación del principio del "país (Comunidad Autónoma) de origen». El gran inconveniente, íntimamente vinculado con los condicionantes a la eficacia supraterritorial antes anunciados, es la intensidad con que ese efecto es acogido en la LGUM. Como luego se intentará aclarar, la LGUM limita de forma excesiva las facultades de la Administración de acogida para corregir o condicionar la aplicación del acto dictado conforme a las normas de origen. Éste es el verdadero problema de la Ley.

Finalmente, se ha de advertir algo que es evidente: esa integración del Derecho foráneo no es plena, sino sólo a efectos aplicativos y para cada caso concreto en virtud de las elecciones de los operadores económicos. Esta evidencia se constata en el sistema de tutela de la unidad de mercado diseñado por los artículos 26 y ss. de la LGUM. La Ley no altera las reglas de distribución territorial de competencias de los órganos jurisdiccionales y mantiene vigente la regla del fuero electivo del artículo 14.1.2. ${ }^{a}$ de la LJCA, sin perjuicio de la legitimación que pueda asumir la CNMC. Acudir ante la Jurisdicción Contencioso-administrativa por la vía «ordinaria» o a través de la CNMC tiene consecuencias en cuanto al ordenamiento de referencia que sirve de norma de control al órgano jurisdiccional competente. Si el operador económico opta por acudir a la vía ordinaria, en virtud del artículo 14.1.2. ${ }^{a}$ de la LJCA, se verá obligado a acudir a los órganos jurisdiccionales competentes de la Comunidad de origen, y la clave está en que el Tribunal Superior de Justicia de esa Comunidad seguirá siendo el único y máximo intérprete de la legislación de esa Comunidad. Ahora bien, si la protección se articula a través de la CNMC (arts. 127 bis y ss. de la LCJA), entonces la competencia será de la Audiencia Nacional [art. 11.1.h) de la LJCA] y el control se limita a valorar el cumplimiento de la LGUM. No hay, pues, intromisión extraña en la integridad del ordenamiento de cada Comunidad Autónoma.

8. Hechas todas estas precisiones, se puede abordar el que aquí se estima como verdadero problema de encaje de la LGUM en la Constitución: los límites establecidos por el legislador estatal a la operatividad del reconocimiento mutuo y a la supraterritorialidad de las actuaciones administrativas en origen y sus efectos en las competencias autonómicas de acogida. Aquí se ha de estar de acuerdo con algunas críticas doctrinales ${ }^{95}$. La clave se encuentra en que, según han sido establecidos esos

95 En S. Muñoz Machado (2014), M. Rebollo (2014) y C. Padrós y J. M. Macías (2014). 
límites, se estaría estableciendo un sistema menos limitativo que el aplicable al reconocimiento mutuo en el contexto europeo ${ }^{96}$, al tiempo que se estaría incurriendo en una gran paradoja: las libertades económicas tendrían mayor protección frente al legislador que los derechos fundamentales más enraizados en la dignidad humana.

Ahora bien, la vulneración de las competencias autonómicas desde esta perspectiva no afecta a una consideración favorable a la integración del principio de reconocimiento mutuo. La discusión, por tanto, no debe ser si la exigencia de una nueva autorización por la Comunidad Autónoma de acogida vulnera o no el contenido esencial de la libertad de empresa, porque es obvio que no incurre $a$ priori en esa vulneración, como tampoco lo hace la omisión de dicha autorización en aplicación del principio de reconocimiento mutuo: ambas opciones son compatibles con el contenido esencial de la libertad de empresa ${ }^{97}$. El problema real es que sólo una opción sea posible para el legislador autonómico y que el legislador estatal predetermine la eficacia supraterritorial de las actuaciones en origen y, por ello, cómo ejercer sus competencias por las CC.AA. de acogida. La cuestión es que las limitaciones impuestas al legislador autonómico para corregir la aplicación del reconocimiento mutuo son excesivamente rígidas.

La LGUM ha optado por la maximización del principio del «país (Comunidad Autónoma) de origen», como se deduce de los artículos 6 y 17 y ss. de la LGUM, fomentando la optimización de la automatici-

96 Resulta llamativa la preocupación que algunos autores han mostrado por la eventual discriminación que la LGUM pudiera generar en operadores económicos comunitarios, en la medida en que sus actividades pudieran someterse a un régimen de excepciones más amplio que el que incorpora la Ley estatal. Sin embargo, esta inquietud no se ha manifestado en sentido contrario, es decir, cuando las relaciones de Derecho Europeo pueden generar discriminaciones inversas en relación con situaciones domésticas similares. El Dictamen del Consejo de Estado 631/2013 afirma que «nada cabe objetar a esta construcción pues (...) se equipara a los ciudadanos españoles con los de los restantes Estados miembros en cuanto a las exigencias específicamente derivadas de normas comunitarias».

97 Esto se podría deducir de las SSTC 26/2012 y 193/2013, cuando no ponen en tela de juicio que el legislador estatal establezca la eliminación «de todos aquellos regímenes de autorización que no estén justificados por una razón imperiosa de interés general».

Esta apreciación marca también dos formas de entender las relaciones jurídico-públicas. Los más críticos parecen dudar de la aplicación de un mecanismo que habilita la realización de actividades económicas sin control administrativo previo. Es evidente que el entendimiento aquí sigue siendo desde el ejercicio del poder público y, por ello, desde la intervención y el control de los ciudadanos. Sin embargo, quienes valoran positivamente el reconocimiento mutuo asumen una aproximación favorable al efectivo ejercicio de los derechos del ciudadano y a la evitación del entorpecimiento no necesario de funciones de intervención previa. Es interesante observar que hemos sido mayoritariamente los administrativistas quienes hemos optado por el primer planteamiento. Sin embargo, y sin ánimo tampoco de generalizar, los trabajos menos críticos son los realizados por algunos constitucionalistas, quienes han entendido el reconocimiento mutuo como un mecanismo de maximización de la libertad de empresa. 
dad del reconocimiento y la eficacia supraterritorial. Aquí se podría encontrar la eventual inconstitucionalidad en la que incurre la Ley: la Comunidad Autónoma de acogida queda predeterminada en la ordenación de las actividades económicas y enclaustrada en un margen limitado de excepciones, de modo que, dentro de ese estrecho margen, goza de funciones de verificación y supervisión muy limitadas.

Sobre los límites al legislador autonómico no creo que se puedan decir muchas más cosas de las ya señaladas en la doctrina ${ }^{98}$, pero la clave se encuentra en que los eventuales límites a la aplicación automática del reconocimiento ni son todos los que de forma general se reconocen en el Derecho Europeo, ni tampoco, siendo la LGUM una norma sin base en una norma comunitaria, son todos los que se pueden derivar de la propia Constitución, de modo que, conjuntamente con las limitadas facultades de verificación conferidas a la Administración de acogida, todo ello puede dar lugar a claros déficits de protección. En concreto, y por lo que se refiere a las facultades de la Administración de acogida, sucede que si el reconocimiento se concibe como automático, la verificación a realizar deberá limitarse a concretar si el operador económico cumple o no con el ordenamiento de origen (tiene licencia o no...). La diversidad en la unidad que describe la unidad de mercado en nuestro ordenamiento exige, sin embargo, un margen de acción mayor, o al menos que sean las propias CC.AA. las que decidan si optan por un sistema de reconocimiento automático o condicionado. Esto significa que las CC.AA. deben poder verificar si la normativa en origen es equivalente a la propia y, por tanto, si impiden la eficacia supraterritorial de la actuación en origen por existir alguna razón de interés general que así lo justifique, imponiendo alguna carga adicional que no sea reiterativa, meramente entorpecedora o disuasoria. Sólo de este modo, aparte de respetarse las competencias de la Comunidad Autónoma de acogida y de condicionar la supraterritorialidad a una decisión de esa misma Comunidad, se salvaguardarían la autonomía y el principio democrático a través de las leyes que aquella Comunidad quisiera dotarse con esa finalidad.

9. Esta última afirmación podría ser criticada pues, como ya hemos indicado, la equivalencia entre ordenamientos opera como una premisa al reconocimiento mutuo que, en un Estado descentralizado como el nuestro, se presume. Si esto es así, se podría decir que el Estado puede optar por un reconocimiento automático que limite las fa-

98 Véase, sobre todo, el voto particular al Dictamen del Consejo de Estado núm. 671/2013 de E. Alonso García y M. Rebollo (2014). 
cultades de verificación por la Comunidad de acogida, precisamente, porque los ordenamientos autonómicos son equivalentes. Esta afirmación a priori no parecería errada, pero omite la trascendencia que el Tribunal Constitucional confiere a la diversidad normativa como principio básico del orden económico: el legislador estatal no puede predeterminar cómo las CC.AA. deben ejercer sus competencias y eliminar prácticamente todas las opciones de diversidad normativa que, dentro de la equivalencia general entre ordenamientos, permitan a las CC.AA. establecer singularidades fundadas en motivos de interés general que puedan ser verificadas cuando la Administración en cuestión actúe como Administración de acogida. En definitiva, que el legislador estatal prevea la posibilidad de un contexto operativo de reconocimiento mutuo no es en sí mismo lo inconstitucional; lo que puede ser inconstitucional es que las CC.AA. no puedan mantener, en su caso, aquellas especifidades que generan la diversidad en la unidad y, en consecuencia, que puedan optar por un modelo de reconocimiento automático o por otro condicionado, y sujeto a previa verificación, gobernado por el principio de proporcionalidad.

Una última precisión en torno a esta cuestión tiene que ver con la mejor adaptación de estas conclusiones con un modelo «federal de integración", como puede ser el europeo, o bien con un modelo descentralizado o de "federalismo devolutivo», como podría ser calificado eufemísticamente el sistema de organización territorial español. Podría afirmarse que en un modelo integrador como el europeo, el principio de subsidiariedad exige que los Estados retengan sus competencias frente a la Unión Europea. Esto podría permitir deducir la coherencia de ese modelo con mecanismos de reconocimiento mutuo no automático. Sin embargo, el Derecho Europeo nos muestra que esta afirmación no se cumple en muchos casos. Aquí cabría alegar que el propio principio de subsidiariedad habilita la actuación de la Unión Europea cuando los objetivos de la acción pretendida no puedan alcanzarse de manera suficiente por los Estados. Este matiz final faculta al legislador europeo a dotar de mayor automatismo al reconocimiento mutuo y a reducir, consecuentemente, las facultades de control por el Estado de acogida.

La conclusión no es muy distinta en un modelo territorial descentralizado. Mientras que la optimización del principio de autonomía incluye un efecto de retención de competencias similar al principio de subsidiariedad pero en sede autonómica (favorable al reconocimiento condicionado), títulos de competencias transversales como el del artículo 149.1.13. ${ }^{a}$ justificarían que el legislador estatal pudiera coordinar el ejercicio de competencias autonómicas previendo como posibi- 
lidad el reconocimiento automático. El matiz entre «imponer» $\mathrm{y}$ «prever como posibilidad» es el elemento que distinguiría un modelo integrativo como el europeo y otro devolutivo como el español. En un modelo dominado por la primacía del Derecho Europeo y el efecto de la preemption se puede justificar el condicionamiento pleno de las competencias que los Estados miembros «ceden hacia arriba»; sin embargo, un modelo devolutivo, limitado por la invalidez que califica la actuación del Estado que se inmiscuya en competencias ajenas, exige mantener ámbitos de decisión en las materias que han sido "cedidas hacia abajo»; dicho de otra manera, esas opciones decisorias no pueden ser precluidas por el legislador estatal. La conclusión es clara: el legislador estatal puede coordinar el ejercicio cooperativo de las competencias autonómicas mediante el mecanismo del reconocimiento mutuo, siempre y cuando deje un margen de opciones razonable para que las CC.AA. opten por un modelo de reconocimiento automático o condicionado y que, en este segundo caso, puedan establecer un elenco razonable de condiciones conforme al marco normativo europeo, constitucional y estatutario.

10. La crítica precedente puede tener también un efecto inverso. Paradójicamente, se ha llegado a afirmar que la LGUM confiere mecanismos a las CC.AA. que podrían hacer casi impracticable el reconocimiento mutuo entre CC.AA. Así lo ha puesto de relieve la crítica doctrinal al recalcar la falta de coherencia del legislador estatal para implantar con efectividad el sistema de reconocimiento mutuo. Entendido literalmente aquel argumento, parecería difícil admitir que la Ley pretendiese imponer una uniformidad rígida que lamine las competencias autonómicas. Insisto, no obstante, que creo que esto no es así. Esa misma crítica serviría para ratificar que el efecto race to the bottom no es tan evidente, por la sencilla razón de que las CC.AA. gozarían de mecanismos para establecer impedimentos a la competencia entre ordenamientos; dicho de otro modo, y según ese argumento, no parece que las CC.AA. más proteccionistas tuvieran que dejar de serlo.

Ahora bien, si lo que se quiere decir es que el legislador estatal ha impuesto un nuevo modelo de intervención administrativa sin dedicar ningún esfuerzo a regular esta cuestión (insistimos en lo ya dicho sobre las deficiencias en la regulación de las facultades de verificación por la Administración de acogida), o que la aplicación de la LGUM va a dar lugar a una gran litigiosidad que condicionará su efectiva aplicación, aquí debemos estar de acuerdo. Sin embargo, la cuestión que ahora se quiere poner de relieve es otra: el problema del reconocimiento mutuo no es sólo si se impone un modelo más o menos rígido; 
el problema es también, y en sentido inverso, si la lealtad de las CC.AA. permitiría cumplir una Ley estatal (más ajustada a los términos aquí defendidos) no imponiendo singularidades injustificadas.

\section{BIBLIOGRAFÍA}

Agudo González, J. (2013): «Sobre la europeización del Derecho y la evolución de la teoría del procedimiento administrativo», REDE, 45.

- (2014): «La Administración del Espacio Administrativo Europeo», RVAP, 99-100.

Ares Álvarez, E. M. ${ }^{\mathrm{a}}$ (2005): «El reconocimiento de cualificaciones profesionales, un paso más hacia la liberalización», Revista de Estudios Europeos, 41.

ARroyo JimÉnEZ, L. (2004): Libre empresa y títulos habilitantes, Madrid: CEPC.

BALLBÉ, M., y PADRós, C. (1997): Estado competitivo y armonización europea, Barcelona: Ariel.

Bocanegra Sierra, R., y García Luengo, J. (2008): "Los Actos Administrativos Transnacionales», Revista de Administración Pública, 177.

CARANTA, R. (1997): "Learning from our Neighbours», Maastricht Journal of European and Comparative Law, 220 (4).

Corso, G. (2007): «Mutuo riconoscimento e norma applicabile», en A. PlaIA, La competizione tra ordinamenti giuridici, Milán: Giuffrè.

De la Quadra-Salcedo Fernández del Castillo, T. (2010): "Libertad de establecimiento y de servicio: ¿Reconocimiento mutuo o país de origen?», REDA, 146.

DE LuCIA, L. (2009): Amministrazione transnazionale e ordinamento europeo, Turín: Giappichelli.

Díez de Velasco Vallejo, M., y Sobrino Heredia, J. M. (2003): «El control jurisdiccional del principio de subsidiariedad en la Unión Europea», en N. ColNERIC et al., Une communauté de droit, Berlín: BWV BerlinerWissenshafts.

Fuentetaja Pastor, J. A. (2008): «El derecho a la buena administración en la Carta de los Derechos Fundamentales de la UE», RDUE, 15.

GaletTA, D.-U. (2009): L'autonomia procedurale degli Stati membri dell'Unione europea: Paradise Lost?,Turín: Giappichelli.

- (2014): «Informal Information Processing in Dispute Resolution Networks», Eur. Pub. Law, 20 (1).

Gambino, S. (2010): «Jurisdicción y justicia entre Tratado de Lisboa, CEDH y ordenamientos nacionales», REDCE, 13.

Garcimartín AlfÉrez, F. J. (2000): «La Sentencia “Centros” del Tribunal de Justicia de las Comunidades Europeas: una visión a través de los comentarios», Rev. Electrónica de Estudios Internacionales, 1.

GARDEÑES SANTIAGO, M. (1999): La aplicación de la regla de reconocimiento mutuo y su incidencia en el comercio de mercancías y servicios en el ámbito comunitario e internacional, Madrid: Eurlex.

Gnes, M. (2004): La Scelta del Diritto. Concorrenza tra ordinamenti, arbitraggi, diritto comune Europeo, Milán: Giuffrè.

GonZÁLEZ Miguel, R. (2007): «Homologación, convalidación y reconocimiento de títulos y estudios extranjeros en España», RDUE, 12.

GoNZÁLEZ VAQuÉ, L. (1997): «Naturaleza y efectos de las cláusulas de reconocimiento mutuo incluidas en las normativas nacionales relativas al mercado interior», Gaceta Jurídica CE, D-27. 
GRIFEU FonT, J. (2014): «La impronta de la Directiva de servicios y de la normativa de transposición interna estatal en las técnicas interventoras urbanísticas. Parada y fonda: la Ley de garantía de la unidad de mercado», RVAP, 98.

Jans, J. H.; De LANGe, R.; Prechal, S., y Widdershoven, R. J. (2007): Europenization of Public Law, Groningen: Eur. Law Pub.

KeESEN, A. (2009): European Administrative Decisions, Groningen: Eur. Law Pub.

LóPEZ EsCUDERO, M. (1993): «La aplicación del principio del reconocimiento mutuo en el Derecho Comunitario», Gaceta Jurídica CE, D-19.

LotTINI, M. (2010): «Correct Application of EU Law by National Public Administrations and Effective Individual Protection», REALaw, 3 (2).

- (2014): «An Instrument of Intensified Informal Mutual Assistance: The IMI and the Protection of Personal Data», Eur. Pub. Law, 20 (1).

MENÉndeZ MENÉNDEZ, A. (1988): «El reconocimiento mutuo de diplomas y títulos para el ejercicio profesional de la medicina», Noticias CEE, 41.

MENÉNDEZ REXACH, A. (1994): «La cooperación, ¿un concepto jurídico?», DA, 240.

MoRel OCAÑa, L. (1994): «Una teoría de la cooperación», DA, 240.

MuÑoz MACHAdo, S. (2014): «Sobre el restablecimiento legal de la unidad de mercado", REDA, 163.

MuselLI, L. (2012): «Administrative Cooperation between Member States: The SOLVIT Network», en L. AmmanNATI, Networks, Turín: Giappichelli.

Nicolin, S. (2005): Il mutuo riconoscimento tra mercato interno e sussisiarietà, Milán: CEDAM.

Nicolussi, A. (2007): «Europa e cosi ddetta competizione tra ordinamenti giuridici», en A. PlaIA, La competizione tra ordinamenti giuridici, Milán: Giuffrè.

Nieto Garrido, E., y Martín Delgado, I. (2010): Derecho Administrativo Europeo en el Tratado de Lisboa, Madrid: Marcial Pons.

Padrós Reig, C., y Macías CASTAÑo, J. M. (2014): «Los instrumentos administrativos de garantía de la unidad de mercado», RAP, 194.

PAREJo Alfonso, L. (2007): «Notas para la construcción dogmática de las relaciones interadministrativas», RAP, 174.

Ponce SolÉ, J. (2010): «Procedimiento administrativo, globalización y buena administración», en J. PONCE, Derecho Administrativo Global, Madrid: Marcial Pons.

Rebollo Puig, M. (2014): «La libertad de empresa tras la ley de garantía de la unidad de mercado", REDA, 163.

RodRÍGUEZ IgLESIAS, G. C. (1977): «La libre circulación de los abogados y los médicos en la comunidad europea. Problemas actuales», Rev. Instituciones Europeas, 4 (1).

RUFFERT, M. (2008): «De la Europeización del Derecho Administrativo a la Unión Administrativa Europea», en F. Velasco y J.-P. SCHNEIDER, La Unión Administrativa Europea, Madrid-Barcelona: Marcial Pons.

- (2011): «European Composite Administration: The transnational administrative act», en O. JANSEN y B. SchÖNDORF-HAUBOLD, The European Composite Administration, Cambridge: Intersentia.

RöHL, H. C. (2011): «Conformity Assessment in European Product Safety Law», en O. Jansen y B. Schöndorf-Haubold, The European Composite Administration, Cambridge: Intersentia.

SCHNEIDER, J.-P. (2007): «Regulation and Europeanisation as Key Patterns of Change in Administrative Law», en M. RUFFERT, The Transformation of Administrative Law in Europe, Groningen: Eur. Law Pub.

- (2008): «Estructuras de la Unión Administrativa Europea», en F. Velasco y J.-P. ScHNEIDER, La Unión Administrativa Europea, Madrid-Barcelona: Marcial Pons. 
Schmidt-Assmann, E. (2003): La teoría general del Derecho Administrativo como sistema, Madrid: Marcial Pons.

- (2011a): «European Composite Administration and the Role of European Administrative Law», en O. JANSEN y B. SchÖNDORF-HAUBOLD, The European Composite Administration, Cambridge: Intersentia.

- (2011b): «Legitimacy and accountability as a basis for administrative organization and activity in Germany», en M. RUFFERT, Legitimacy in European Administrative Law, Groningen: Eur. Law Pub.

SchÜtZe, R. (2010): «From Rome to Lisbon: "Executive Federalism" in the (New) EU», CMLR, 47.

SchwARZE, J. (2006): European Administrative Law, Luxemburgo: Thomson.

Tornos MAS, J. (2014): «La Ley 20/2013, de 9 de diciembre, de garantía de la unidad de mercado. En particular, el principio de eficacia», $R E A F, 19$.

ValaguzZa, S. (2008): La frammentazione della fatti speci en el Diritto Amministrativo a conformazione Europea, Milán: Giuffrè.

VARGas VASSERot, C. (2004): «El efecto Delaware en el Derecho cooperativo español», en el XVIII Seminario Nacional y III Internacional de Investigación en Materia de Sociedades Cooperativas y Otras Organizaciones de Participación, Madrid, 27 de febrero.

VESPERINI, G. (2011): Il vincolo europeo sui diritti amministrativi nazionali, Milán: Giuffrè.

VIOLA, F. (2007): «Il diritto come scelta», en A. PlAIA, La competizione tra ordinamenti giuridici, Milán: Giuffrè.

Velasco Caballero, F. (2011): «The legitimacy of the Administration in Spain», en M. RUFFERT, Legitimacy in European Administrative Law, Groningen: Eur. Law Pub.

- (2014): Derecho Público más Derecho Privado, Madrid-Barcelona-Buenos Aires-São Paulo: Marcial Pons.

Von Bogdandy, A. (2013): «El Derecho Administrativo en el Espacio Jurídico Europeo», en A. von Bogdandy y O. Mir PuigPelat, El Derecho Administrativo en el espacio jurídico europeo, Valencia: Tirant lo Blanch.

WetTNER, F. (2011): «The General Law of Procedure of EC Mutual Administrative Assistance», en O. JANSEN y B. SchÖNDORF-HAUBOLD, The European Composite Administration, Cambridge: Intersentia. 